\title{
Neuropsychology, autobiographical memory, and hippocampal volume in "younger" and "older" patients with chronic schizophrenia
}

\section{Christina Josefa Herold ${ }^{1}$ *, Marc Montgomery Lässer ${ }^{1}$, Lena Anna Schmid ${ }^{1}$, Ulrich SeidI ${ }^{2}$, Li Kong ${ }^{1}$, Iven Fellhauer ${ }^{1}$, Philipp Arthur Thomann ${ }^{3}$, Marco Essig ${ }^{4}$ and Johannes Schröder ${ }^{1,5}$}

\author{
1 Section of Geriatric Psychiatry, Department of General Psychiatry, University of Heidelberg, Heidelberg, Germany \\ ${ }^{2}$ Center for Mental Health, Klinikum Stuttgart, Stuttgart, Germany \\ ${ }^{3}$ Department of General Psychiatry, Center of Psychosocial Medicine, University of Heidelberg, Heidelberg, Germany \\ ${ }^{4}$ German Cancer Research Center, Heidelberg, Germany \\ ${ }^{5}$ Institute of Gerontology, University of Heidelberg, Heidelberg, Germany
}

\section{Edited by:}

Gretchen Hermes, Yale University, USA

\section{Reviewed by:}

John Gigg, University of Manchester United Kingdom

Bernhard J. Mitterauer,

Volitronics - Institute for Basic

Research Psychopathology and Brain

Philosophy, Austria

${ }^{*}$ Correspondence:

Christina Josefa Herold, Section of Geriatric Psychiatry, Department of General Psychiatry, University of Heidelberg, Voßstr. 4, Heidelberg 69115, Germany

e-mail: christina-j.herold@med. uni-heidelberg.de
Despite a wide range of studies on neuropsychology in schizophrenia, autobiographical memory (AM) has been scarcely investigated in these patients. Hence, less is known about AM in older patients and hippocampal contribution to autobiographical memories of varying remoteness. Therefore, we investigated hippocampal volume and AM along with important neuropsychological domains in patients with chronic schizophrenia and the respective relationships between these parameters. We compared 25 older patients with chronic schizophrenia to 23 younger patients and an older healthy control group $(N=21)$ with respect to $A M$, additional neuropsychological parameters, and hippocampal volume. Personal episodic and semantic memory was investigated using a semi-structured interview. Additional neuropsychological parameters were assessed by using a battery of standard neuropsychological tests. Structural magnetic resonance imaging data were analyzed with an automated region-of-interest procedure. While hippocampal volume reduction and neuropsychological impairment were more pronounced in the older than in the younger patients, both groups showed equivalent reduced AM performance for recent personal episodes. In the patient group, significant correlations between left hippocampal volume and recent autobiographical episodes as well as personal semantic memories arose. Verbal memory and working memory were significantly correlated with right hippocampal volume; executive functions, however, were associated with bilateral hippocampal volumes. These findings underline the complexity of AM and its impairments in the course of schizophrenia in comparison to rather progressive neuropsychological deficits and address the importance of hippocampal contribution.

Keywords: chronic schizophrenia, autobiographical memory, hippocampus, structural magnetic resonance imaging, episodic memory, semantic memory, neuropsychology

\section{INTRODUCTION}

Volumetric alterations in a variety of memory-associated cerebral regions such as the hippocampus $(1,2)$ as well as mnestic deficits have been frequently reported in schizophrenia (3-5). However, older patients with a chronic course of the disease have been scarcely investigated (6), although this patient group is expected to increase given demographic changes (7).

Hippocampal volume reductions of $2-4 \%$ were reported in schizophrenia $(8,9)$, and a significant volumetric reduction seems to be comparable in first-episode and chronic patients (2). Furthermore, a selective reduction of anterior (10-15) and posterior hippocampal volume (16-21) was repeatedly described in patients with schizophrenia. A regional specific pattern of hippocampal volume loss is of interest due to possible functional implications of hippocampal connections and cellular organization (22), as described in the hippocampal encoding/retrieval (HIPER) model (23): hippocampal activity (via positron emission tomography,
PET) associated with memory encoding is primarily located in the anterior part; during memory retrieval, mainly, the posterior part is activated. Besides these findings, several studies reported specific relationships between hippocampal volume and cognitive abilities in schizophrenia $(24,25)$. Nevertheless, older patients with a duration of the disease of several decades were less frequently examined, with hippocampal volume reductions of $10-33 \%$ in relation to healthy comparison subjects (26-28).

Similarly, autobiographical memory (AM), which includes both personal episodic and semantic memory, was scarcely examined in patients with schizophrenia and studies focused primarily on younger patients (29-33). Our previous results from 33 older schizophrenic patients (mean age 52.03 \pm 8.76 ) indicate consistently with these studies that poorer episodic and semantic AM performance of the patients is associated with left hippocampal volume reduction (34). However, differences in AM performance between older and younger patients with chronic schizophrenia 
are unknown as well as the relationships between AM from recent and remote lifetime periods and hippocampal volume. Therefore, we enlarged the patient sample described above and contrasted the respective results of elderly patients to that of an age-matched healthy control group and younger patients with a chronic course of the disease.

Concerning long-term memories - as assessed by autobiographical interviews - the contribution of hippocampus to recent and remote memories is discussed by two major theories making different predictions: The standard model of consolidation postulates a gradual process of reorganization of declarative memories, which become independent of medial temporal lobe structures as cortical regions become increasingly engaged (35-37). According to multiple-trace-theory, the hippocampus is permanently involved in remembering detailed and vivid episodic memories, while semantic memories become independent of this structure (38-40). Based on multiple-trace-theory, the transformation hypothesis proposes that during retrieval of vivid and detailed episodic memories, processes of re-encoding by the hippocampus allow the extraction of regularities. These semantic memories containing schematic and abstract information are represented by neocortical structures $(41,42)$.

In the present study, we used an automated region-of-interest analysis technique to examine hippocampal volume of older patients with chronic schizophrenia in contrast to younger patients and healthy controls. Given a functional segregation of anterior and posterior hippocampus, a differentiating analysis may help to identify the underlying pathological processes in schizophrenia and the associated cognitive implications. Considering different lifetime periods, we aimed to analyze AM performance of the respective groups and the specific associations between hippocampal volume and recent and remote episodic and semantic AM, respectively. A battery of standard neuropsychological tests was additionally applied, which require verbal memory, short-term and working memory, information processing speed, executive functions, and remote semantic memory to contrast with AM performance.

We hypothesized (1) hippocampal volume reductions and (2) $\mathrm{AM}$ as well as additional neuropsychological deficits especially in the older patient group in contrast to healthy controls. Furthermore, we expected (3) AM and (4) additional neuropsychological parameters of memory and executive functions to be correlated with hippocampal volume in both patients with schizophrenia and healthy controls.

\section{MATERIALS AND METHODS \\ SUBJECTS}

Twenty-five older ( $55.92 \pm 6.85$ years of age) and 23 younger patients ( $32.78 \pm 7.00$ years of age) with DSM-IV (43) schizophrenia or schizoaffective disorder were recruited from the residential care St. Thomas e.V., Heidelberg, and the Department of Psychiatry, University of Heidelberg. Data from 33 patients had been analyzed in a previous study (34). Psychopathology was rated by means of the Scale for the Assessment of Positive Symptoms (SAPS) (44), the Scale for the Assessment of Negative Symptoms (SANS) (45), the Brief Psychiatric Rating Scale (BPRS) (46), and the Apathy Evaluation Scale (AES) (47), respectively.
Twenty-one healthy comparison subjects $(53.67 \pm 8.00$ years of age) were recruited through newspaper advertisement. All groups were closely matched $(p>0.20)$ with regard to sex ( $\%$ male: older patients: 76.00, younger patients 60.90 , healthy controls 57.10 ) and education (years of education: older patients $13.28 \pm 3.30$, younger patients $12.61 \pm 1.80$, healthy controls $13.90 \pm 2.12$ ); in addition, healthy control subjects and older patients were matched for age $(p>0.80)$. All subjects were right-handed (48). Exclusion criteria for all participants were: (1) a lifetime history of neurological disorder, head injury, or substance dependency, (2) an axis II disorder, (3) mental retardation, (4) being not fluent in German. The study was approved by the ethics committee of the medical faculty of Heidelberg University and all participants gave written informed consent after the procedures of the study had been fully explained.

\section{NEUROCOGNITIVE ASSESSMENT}

Autobiographical memory performance was assessed using a semistructured autobiographical interview (49), adapted from Kopelman et al. (50). Autobiographical events and facts from the following five lifetime periods were addressed: preschool (up to 6 years of age), primary school (from 6 to 11 years of age), secondary school (from 11 years of age to graduation), early adulthood (from graduation to 35 years of age), and recent 5 years. From each lifetime period, the participants were asked to report details of one autobiographical event (max. 11 points) and five autobiographical facts (max. 5 points). The scoring parameters and the control for delusional memories are described elsewhere in detail (34). In consideration of the younger patient group, we restricted our analyses to memories from four lifetime periods. Our analyses refer to the total score of the remembered details (max. 44 points) and the total score of personal facts (max. 20 points); in case of remote memories, we added scores from lifetime periods 1 and 2 (preschool and primary school); for recent memories, we added scores from lifetime periods 3 and 4 (secondary school and early adulthood); respectively. The interview shows a sufficient internal consistency (Cronbach's $\alpha$ ) of the two scales. In a previous study, the inter-rater reliability ranged from 0.954 to 0.979 (51).

A comprehensive neuropsychological test battery including tests of verbal memory, short-term and working memory, information processing speed, executive functioning as well as remote semantic memory was administered to each subject. Verbal memory was tested with the subtests Logical Memory I (immediate recall) and II (delayed recall) from the Wechsler memory scalerevised (WMS-R) (52); short-term and working memory were evaluated using the Digit Span forward and backward from the WMS-R. The assessment of processing speed and executive function was based on Trail Making Test (TMT) version A and B (53). Remote semantic memory was tested via recognition performance of famous people using the Bielefelder Famous Faces Test (BFFT) (54).

The completion of the whole test battery took approximately $3 \mathrm{~h}$ and was organized in two or more sessions.

\section{MRI DATA ACQUISITION}

The magnetic resonance imaging (MRI) data were obtained at the German Cancer Research Centre using a 3.0 Tesla 
scanner (SIEMENS MAGNETOM TrioTim syngo MR B15). A high-resolution T1-weighted magnetization prepared rapid gradient echo (MP-RAGE) sequence was performed with the following acquisition parameters: 160 sagittal slices, voxel size $=1.0 \mathrm{~mm} \times 1.0 \mathrm{~mm} \times 1.0 \mathrm{~mm}$, image matrix $=256 \times 256$, flip angle $9^{\circ}, \mathrm{TR}=2300 \mathrm{~ms}, \mathrm{TE}=2.98 \mathrm{~ms}, \mathrm{TI}=900 \mathrm{~ms}$.

\section{MRI DATA ANALYSIS}

Magnetic Resonance Imaging data analysis was carried out with FSL (FMRIB Software Library v 4.1.7, Oxford Centre for Functional MRI of the Brain) $(55,56)$. FMRIB's Integrated Registration and Segmentation Tool (FIRST v 1.2) was used to segment and analyze volumes of left and right hippocampus (57). The segmentation routine FIRST is a mesh model based tool for segmenting subcortical brain structures utilizing a library of manually segmented images obtained from the Center for Morphometric Analysis, Massachusetts General Hospital, Boston. Additional information about this method is given elsewhere $(34,58)$. The hippocampus volume comprised the dentate gyrus, the ammonic subfields (CA1-4), the prosubiculum, and the subiculum [cf. (58, 59)]. After segmentation of the hippocampus, which is based on shape models and voxel intensities, the structure was divided in an anterior and a posterior section by the coordinates of the center of gravity (posterior: $\mathrm{Y}$ axis $>0$, anterior: $\mathrm{Y}$ axis $<0$ ) (59). Results were given in $\mathrm{mm}^{3}$; for volumetric calculations, default parameters were used.

The calculation of intracranial volume (ICV) was conducted by summing-up the volumes of gray matter, white matter, and cerebrospinal fluid arrived by using the T1-weighted scans via SPM5 software (http://www.fil.ion.ucl.ac.uk/spm).

\section{STATISTICAL ANALYSIS}

SPSS version 17.0. was used for statistical analysis; in all comparisons, the alpha level was set at $p<0.05$. Group differences in demographic and clinical characteristics were investigated via univariate analysis of variance (ANOVA), independent group $t$-test, or $\chi^{2}$-test, respectively. Repeated measures ANOVAs with group (younger vs. older patients vs. healthy subjects) as between-subject factor and period as within-subject factor (all lifetime periods: 1-4, early periods: $1-2$, late periods: $3-4$ ) were conducted for the AM scores. Greenhouse-Geisser correction (60) was applied in case of violation of sphericity. The additional neuropsychological data were subjected to multivariate analysis of variance (MANOVA) with group as between-subject factor. Volumetric group differences were also calculated via MANOVA with ICV as covariate, which accounts for potential differences in premorbid brain size and hence considers brain size associated variance. Post hoc analyses were performed by using the Bonferroni formula; in case of violation of the homogeneity of variance assumption, the Games-Howell test was applied [(61) p. 134]. Partial correlations (two-tailed) were examined to analyze associations between hippocampal volume and AM performance and neuropsychological scores, respectively. These analyses were done for healthy controls and patients separately, the two patient groups were merged. We adjusted for the effects of educational level due to possible influences of this variable on cognitive performance.

\section{RESULTS}

\section{CLINICAL CHARACTERISTICS}

As described above, the two patient groups differed significantly with respect to age and as a matter of fact with respect to duration of illness $(p \leq 0.000)$-as age at illness onset differed not significantly between the groups $(p>0.20)$ - with a mean duration of illness (calculated since initial diagnosis) of 31 years and 11 years, respectively (Table 1 ). The majority of the older patients $(68 \%)$ live in psychiatric long-term units in contrast to about $35 \%$ of the younger patients $\left(\chi^{2}=5.30 ; p=0.02 ; \mathrm{df}=1\right)$. Regarding antipsychotic medication indicated in chlorpromazine (CPZ)

Table 1 | Clinical characteristics of the patients

\begin{tabular}{|c|c|c|c|c|}
\hline & $\begin{array}{l}\text { Older patients } \\
\qquad \begin{array}{c}N=25 \\
M(S D)\end{array}\end{array}$ & $\begin{array}{l}\text { Younger patients } \\
\qquad \begin{array}{c}N=23 \\
M(\mathrm{SD})\end{array}\end{array}$ & $T(\mathbf{d f})^{\mathrm{a}}$ & $p$ \\
\hline Duration of illness, years & $31.36(10.54)$ & $10.48(6.40)$ & $8.22(46)$ & 0.000 \\
\hline Age at illness onset, years & $24.56(8.63)$ & $22.30(4.73)$ & $-1.13(37,84)$ & 0.264 \\
\hline Hospitalized (\%) & 68.00 & 34.78 & & $0.021^{b}$ \\
\hline Additional antidepressive medication, $N$ & 10 & 10 & & $0.807^{b}$ \\
\hline Additional benzodiazepines, $N$ & 2 & 1 & & $0.576^{b}$ \\
\hline BPRS & $35.28(9.21)$ & $41.43(9.07)$ & $2.33(46)$ & 0.024 \\
\hline SAPS & $13.92(14.69)$ & $19.48(16.42)$ & $-1.24(46)$ & 0.222 \\
\hline SANS & $31.08(20.65)$ & $34.83(25.60)$ & $-0.56(46)$ & 0.578 \\
\hline
\end{tabular}

AES, Apathy Evaluation Scale; AT, atypical antipsychotics; AT+T, atypical and typical antipsychotics; BPRS, Brief Psychiatric Rating Scale; CPZ, chlorpromazine; SANS, Scale for the Assessment of Negative Symptoms; SAPS, Scale for the Assessment of Positive Symptoms; T, typical antipsychotics.

${ }^{a}$ t-test (df, degrees of freedom).

${ }^{b} \chi^{2}$-test. 
equivalents (62), the younger patients received significantly higher doses than the older patient group $(p<0.05)$. Symptom severity differences were found with respect to BPRS score, which is significantly higher in younger than in older patients $(p<0.03)$. Negative symptoms predominated in both patient groups $(p \leq 0.02)$.

\section{HIPPOCAMPAL VOLUME}

As hypothesized, the MANOVA revealed significant group differences with respect to left and right hippocampus, as well as the respective subregions of anterior and posterior sections (Table 2). Post hoc tests showed reduced hippocampal volumes of the older patient group in comparison to the age-matched healthy control group $(0.000 \leq p<0.04)$ and to the younger patients $(0.000 \leq p<0.02)$. In case of right anterior hippocampus, this difference was significant for older in contrast to younger patients $(p=0.007)$, with a trend-level significant difference to healthy subjects $(p=0.066)$.

The volume decrease of the older patients - based on $100 \%$ in the control group - accounts for $13.95 \%$ in left and $8.55 \%$ in right hippocampus.

No significant correlations of hippocampal volumes with $\mathrm{CPZ}$ equivalents or psychopathological symptom scores arose $(p>0.09)$. When controlled for age, the correlations between left and right hippocampal volumes and duration of illness were not significant $(p>0.50)$. Repeated analyses based on relative hippocampal volumes (quotient of hippocampal volume and ICV) yielded concurrent results.

\section{AUTOBIOGRAPHICAL MEMORY AND NEUROPSYCHOLOGICAL PERFORMANCE}

The repeated measures ANOVAs yielded a significant main effect of group for episodic details and semantic AM from four lifetime periods (Table 3). Younger and older patients achieved comparable performances in both AM scores $(p>0.40)$. However, post hoc tests showed significant impairments of the older patient group in comparison to the healthy subjects concerning episodic $(p=0.018)$ and semantic AM $(p=0.022)$. In Figure 1, the AM performance of patients and healthy controls is given in percent - based on $100 \%$ for the maximal score.

The effect of period reached significance for episodic $\left(p<0.02 ; F=4.05 ;\right.$ partial $\left.\eta^{2}=0.06 ; \mathrm{df}=2.69\right)$ and semantic AM $\left(p \leq 0.000 ; F=29.91\right.$; partial $\left.\eta^{2}=0.31 ; \mathrm{df}=2.59\right)$. Post hoc tests revealed better performances for recent in contrast to remote memories (period 1 vs. period $4 p \leq 0.001$; period 2 vs. period 4 $p \leq 0.05)$.

Table 2 | Hippocampal volumes $\left(\mathrm{mm}^{3}\right)$ of patients and healthy controls.

\begin{tabular}{|c|c|c|c|c|c|c|c|}
\hline & $\begin{array}{l}\text { Older patients } \\
\qquad \begin{array}{c}N=25 \\
M(\mathrm{SD})\end{array}\end{array}$ & $\begin{array}{l}\text { Younger patients } \\
\qquad \begin{array}{c}N=23 \\
M(\mathrm{SD})\end{array}\end{array}$ & $\begin{array}{l}\text { Healthy controls } \\
\qquad \begin{array}{c}N=21 \\
M(\mathrm{SD})\end{array}\end{array}$ & $F(\mathbf{d f})^{\mathrm{a}}$ & $p$ & Partial $\eta^{2}$ & Post hoc ${ }^{b}$ \\
\hline Left hippocampus & 3377.24 (593.49) & $3997.91(358.62)$ & 3924.95 (381.19) & $16.22(2,65)$ & 0.000 & 0.333 & $\mathbf{O}<\mathrm{Y}, \mathbf{H}$ \\
\hline Right hippocampus & 3659.24 (688.05) & 4079.44 (397.97) & 4001.19 (392.20) & $5.52(2,65)$ & 0.006 & 0.145 & $\mathbf{O}<\mathbf{Y}, \mathbf{H}$ \\
\hline Left anterior hippocampus & $1421.84(244.16)$ & $1674.52(158.60)$ & 1647.48 (197.75) & $13.14(2,65)$ & 0.000 & 0.288 & $\mathbf{O}<\mathbf{Y}, \mathbf{H}$ \\
\hline Left posterior hippocampus & 1955.40 (357.44) & 2323.39 (219.75) & 2277.48 (198.87) & $16.91(2,65)$ & 0.000 & 0.342 & $\mathbf{O}<\mathrm{Y}, \mathrm{H}$ \\
\hline Right anterior hippocampus & 1539.08 (273.44) & 1717.83 (144.25) & 1665.24 (187.77) & $5.44(2,65)$ & 0.007 & 0.143 & $\mathbf{O}<\mathbf{Y}$ \\
\hline Right posterior hippocampus & $2120.16(420.42)$ & $2361.61(266.41)$ & 2335.95 (221.95) & $5.24(2,65)$ & 0.008 & 0.139 & $\mathbf{O}<\mathrm{Y}, \mathrm{H}$ \\
\hline
\end{tabular}

$H$, healthy controls; $O$, older patients, $Y$, younger patients.

${ }^{a}$ MANOVA, ICV as covariate (df, degrees of freedom).

${ }^{b}$ Bonferroni (5\%).

Table 3 | Autobiographical memory performance of patients and healthy controls

\begin{tabular}{|c|c|c|c|c|c|c|c|}
\hline & $\begin{array}{l}\text { Older patients } \\
\qquad \begin{array}{c}N=25 \\
M(S D)\end{array}\end{array}$ & $\begin{array}{l}\text { Younger patients } \\
\qquad \begin{array}{c}N=23 \\
M(\mathrm{SD})\end{array}\end{array}$ & $\begin{array}{l}\text { Healthy controls } \\
\qquad \begin{array}{c}N=21 \\
M(\mathrm{SD})\end{array}\end{array}$ & $F(\mathbf{d f})^{\mathbf{a}}$ & $p$ & Partial $\eta^{2}$ & Post hoc ${ }^{b}$ \\
\hline Episodic details, periods 1-4 & $21.12(14.47)$ & 25.57 (13.26) & $30.62(7.76)$ & $3.41(2,66)$ & 0.039 & 0.094 & $\mathbf{O}<\mathbf{H}$ \\
\hline Episodic details, periods 1-2 & $10.28(7.66)$ & $12.43(7.22)$ & $12.90(5.34)$ & $1.01(2,66)$ & 0.371 & 0.030 & \\
\hline Episodic details, periods 3-4 & $10.84(8.11)$ & $13.13(7.25)$ & $17.71(4.46)$ & $5.80(2,66)$ & 0.005 & 0.149 & $\mathbf{O}, \mathbf{Y}<\mathrm{H}$ \\
\hline Semantic, periods $1-4$ & $16.80(3.07)$ & $17.74(2.26)$ & $18.81(1.75)$ & $3.81(2,66)$ & 0.027 & 0.103 & $\mathbf{O}<\mathbf{H}$ \\
\hline Semantic, periods 1-2 & $7.64(2.10)$ & $8.13(1.79)$ & $9.00(1.30)$ & $3.35(2,66)$ & 0.041 & 0.092 & $\mathbf{O}<\mathbf{H}$ \\
\hline Semantic, periods 3-4 & $9.16(1.34)$ & $9.61(0.78)$ & $9.81(0.60)$ & $2.66(2,66)$ & 0.077 & 0.075 & \\
\hline
\end{tabular}

$H$, healthy controls; $O$, older patients, $Y$, younger patients.

${ }^{a}$ Repeated measures ANOVA (df, degrees of freedom).

${ }^{b}$ Games-Howell Test (5\%). 
The interaction group $\times$ period indicated in case of semantic AM a non-significant effect $(p>0.25)$, in case of episodic AM a trend level significance $\left(p=0.07 ; F=2.01\right.$; partial $\eta^{2}=0.06$; $\mathrm{df}=5.38$, with raw scores showing a recency effect in the control group. In both patient groups, the recency effect was less pronounced and the performance for the periods 2 and 3 in the older patient group (period 2 in the younger patients) was reduced in comparison to period 1.

Separate analyses for recent and remote lifetime periods (period 1 and 2 vs. period 3 and 4 ) yielded no significant main or interaction effects for remote episodic AM $(p>0.20)$, in contrast to recent episodic AM, which showed a significant effect for group. Healthy control subjects outperformed older $(p=0.002)$ and younger patients $(p<0.04)$, with no significant difference between the patient groups $(p>0.50)$. The analysis of remote

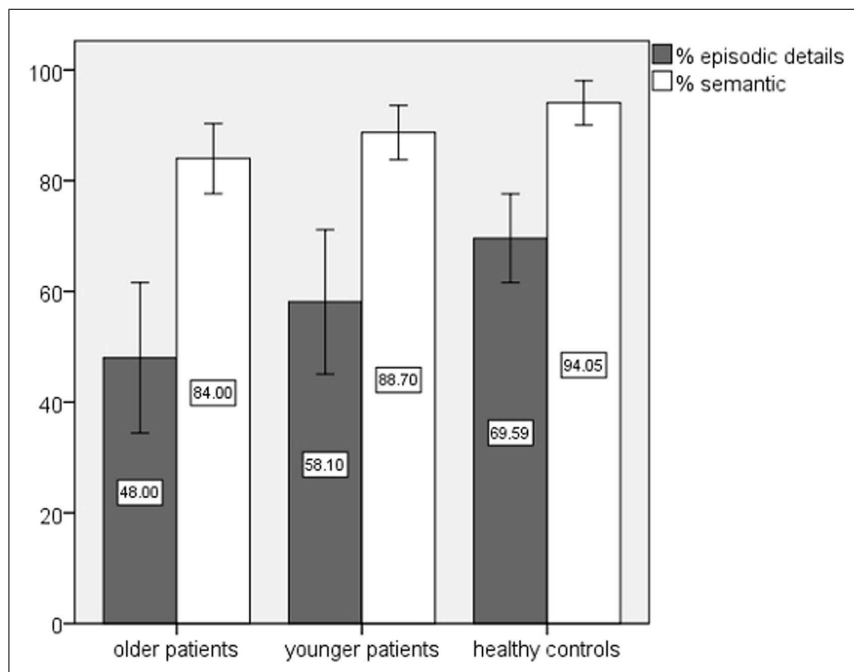

FIGURE 1 | Autobiographical memory performance of patients and healthy controls in percent. semantic memories revealed a significant effect of group, showing that the older patients reported fewer autobiographical facts than their healthy counterparts $(p<0.03)$, again the difference between the patient groups did not reach significance $(p>0.60)$. In case of recent semantic memories, no significant effects were found $(p \geq 0.07)$.

Episodic but not semantic AM was significantly correlated with education in the patient group $(r=0.30 ; p<0.04 ; \mathrm{df}=48)$. Apart from this, episodic and semantic AM sumscores were not significantly correlated with age, duration of illness, and CPZ equivalents $(p>0.10)$, but episodic AM was significantly negatively correlated with SANS $(r=-0.41 ; p=0.004 ; \mathrm{df}=48)$ and AES sumscores $(r=-0.33 ; p=0.02 ; \mathrm{df}=48)$.

With regard to the additional neuropsychological parameters, the older patient group performed significantly worse in tests measuring verbal memory (Logical Memory I and II), information processing speed, and executive functions (TMT A and B), and remote semantic memory (BFFT) as well $(0.000 \leq p \leq 0.007)$. No significant group differences were found in short-term and working memory (Table 4; Figure 2). In case of Logical Memory $(p \leq 0.000)$ and TMT B $(p=0.05)$ also, the younger patients showed marked impairments in comparison to the even older healthy control group, with performance levels between the older patients and the healthy probands.

No significant correlations between neuropsychological parameters and CPZ-equivalents emerged $(p>0.05)$. Significant correlations arose between level of education and "Logical Memory I," "Digit Span backward" $(0.38<r<0.44 ; 0.001<p<0.006$; $\mathrm{df}=48)$, “TMT B" $(r=-0.41 ; p=0.004 ; \mathrm{df}=48)$, and "BFFT" $(r=0.41 ; p=0.006 ; \mathrm{df}=43)$. "Logical Memory I and II" $(-0.49<r<-0.58 ; \quad p \leq 0.000 ; \quad \mathrm{df}=48)$, “TMT A and B" $(0.30<r<0.36 ; p \leq 0.03 ; \mathrm{df}=48)$, and "BFFT" $(r=-0.32$; $p=0.04 ; \mathrm{df}=43$ ) were significantly correlated with SANS sumscore. Accordingly, we found significant correlations between AES sumscore and "Logical Memory I and II" $(-0.46<r<-0.56$; $p \leq 0.001 ; \mathrm{df}=48)$, "Digit Span backward" $(r=-0.36 ; p=0.01$; $\mathrm{df}=48)$, and "TMT A and TMT B" $(0.28<r<0.40 ; 0.005$

Table 4 | Neuropsychological performance of patients and healthy controls.

\begin{tabular}{|c|c|c|c|c|c|c|c|}
\hline & $\begin{array}{l}\text { Older patients } \\
\qquad \begin{array}{c}N=\mathbf{2 5} \\
M \text { (SD) }\end{array}\end{array}$ & $\begin{array}{l}\text { Younger patients } \\
\qquad \begin{array}{c}N=\mathbf{2 3} \\
M(\mathrm{SD})\end{array}\end{array}$ & $\begin{array}{l}\text { Healthy controls } \\
\qquad \begin{array}{l}N=21 \\
M(\mathrm{SD})\end{array}\end{array}$ & $F(\mathbf{d f})^{\mathbf{a}}$ & $p$ & Partial $\eta^{2}$ & Post hoc ${ }^{b}$ \\
\hline Logical memory I & $14.60(6.60)$ & $21.04(8.85)$ & $29.95(5.12)$ & $27.02(2,66)$ & 0.000 & 0.450 & $\mathrm{O}<\mathrm{Y}<\mathrm{H}$ \\
\hline Logical memory II & $9.96(5.86)$ & $16.30(7.90)$ & $25.71(5.03)$ & $34.73(2,66)$ & 0.000 & 0.513 & $\mathbf{O}<\mathrm{Y}<\mathrm{H}$ \\
\hline Digit span forward & $6.88(1.92)$ & $7.43(1.73)$ & $7.81(2.14)$ & $1.36(2,66)$ & 0.264 & 0.040 & \\
\hline Digit span backward & $5.16(1.80)$ & $5.74(1.79)$ & 6.38 (1.69) & $2.74(2,66)$ & 0.072 & 0.077 & \\
\hline Trail making test $A$ & $61.63(41.66)$ & 36.52 (15.85) & $34.76(12.11)$ & $7.09(2,66)$ & 0.002 & 0.177 & $\mathbf{O}>\mathrm{H}, \mathrm{Y}$ \\
\hline Trail making test B & 188.25 (62.63) & $101.17(59.41)$ & $68.48(21.56)$ & $32.77(2,66)$ & 0.000 & 0.498 & $\mathbf{O}>\mathrm{Y}>\mathrm{H}$ \\
\hline Bielefelder famous faces test ${ }^{c}$ & $2.10(0.38)$ & $2.33(0.48)$ & $2.43(0.24)$ & $3.92(2,57)$ & 0.025 & 0.121 & $\mathbf{O}<\mathbf{H}$ \\
\hline
\end{tabular}

$H$, healthy controls; $O$, older patients, $Y$, younger patients.

${ }^{a}$ MANOVA (df, degrees of freedom).

${ }^{b}$ Bonferroni (5\%), TMT B and BFFT: Games-Howell Test (5\%).

${ }^{c}$ Reduced $N$ in groups: 23 older patients, 20 younger patients, 17 healthy controls. 
$<p<0.05 ; \mathrm{df}=48)$. SAPS and BPRS sumscores were not significantly correlated with the neuropsychological parameters $(p>0.10)$, with the exception of BFFT, which showed a significant correlation with SAPS sumscore $(r=0.33 ; p=0.03$; $\mathrm{df}=43)$.

\section{CORRELATIONS BETWEEN HIPPOCAMPAL VOLUME AND AUTOBIOGRAPHICAL MEMORY}

In the patient group as a whole, correlational analyses between hippocampal volumes and AM revealed several significant relationships, as can be seen in Table 5. Episodic AM performance was significantly correlated with left $(r=0.29 ; p=0.05)$ and especially left anterior $(r=0.31 ; p<0.04)$ hippocampal volume. Further analyses showed that this association can mainly be explained

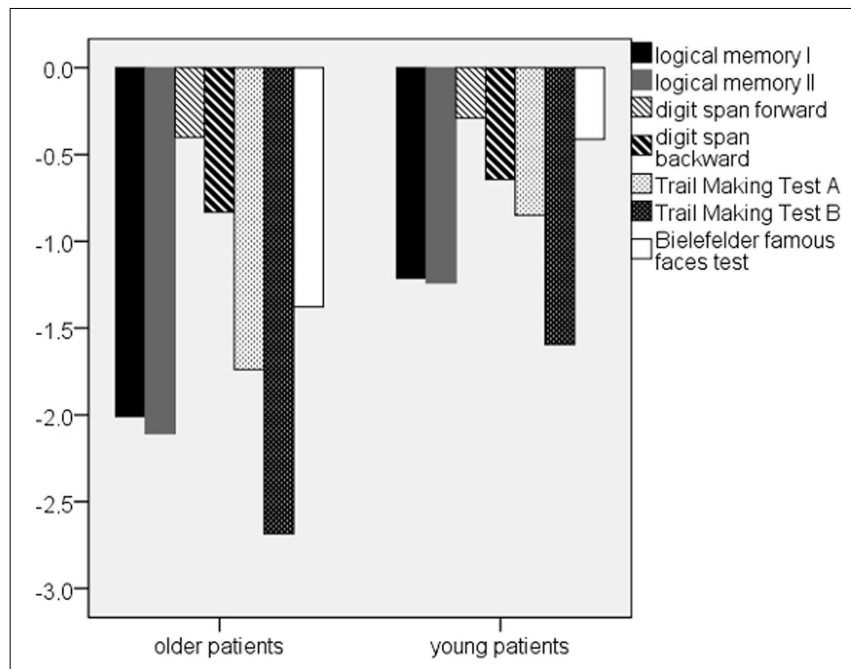

FIGURE 2 | Patients' z-scores of the additional neuropsychological parameters. Note: $z$-scores are based on WMS-R/TMT, in case of BFFT on healthy control data. by recent autobiographical episodic details (lifetime period 3-4), which were significantly correlated with left anterior hippocampus $(r=0.30 ; p<0.05)$. On the other hand, semantic autobiographical memories from the four lifetime periods were significantly associated with left anterior and posterior hippocampal volumes independent of their recency $(0.29<r<0.31 ; 0.03<p<0.05)$.

In the healthy control group, left anterior and posterior hippocampus were significantly associated with semantic autobiographical memories, especially with memories from childhood periods $(0.40<r<0.60 ; 0.005<p<0.05)$. In contrast, the episodic autobiographical memories showed no significant correlations with hippocampal volume $(p \geq 0.09)$ (Table 6).

\section{CORRELATIONS BETWEEN HIPPOCAMPAL VOLUME AND NEUROPSYCHOLOGY}

Several significant correlations between particularly right hippocampal volume and the additional neuropsychological parameters of verbal memory, working memory, and executive functions emerged (Table 7). Verbal memory scores were found to significantly correlate with right anterior and posterior hippocampal volumes $(0.25<r<0.35 ; 0.01<p<0.05)$. In addition, left and right anterior hippocampus showed significant positive associations with working memory $(0.25<r<0.35 ; 0.02<p<0.05)$. TMT B had broad significant negative relationships with left and right anterior and posterior hippocampus $(-0.40<r<-0.50$; $0.000<p<0.005)$. No significant associations with hippocampal volume could be reported for short-term memory, processing speed (TMT A), and remote semantic memory (BFFT) $(p>0.10)$.

In the healthy control group, the correlations between hippocampal volume and neuropsychological parameters failed significance $(p>0.05)$.

\section{DISCUSSION}

The present study yielded the following main findings, which are discussed in the subsequent sections: (1) a pronounced hippocampal volume reduction in older patients with schizophrenia,

Table 5 | Partial correlations ${ }^{a}$ between hippocampal volume and autobiographical memory in the patient group.

\begin{tabular}{|c|c|c|c|c|c|c|c|}
\hline Hippocampus & & Left & Right & Left anterior & Left posterior & Right anterior & Right posterior \\
\hline \multicolumn{8}{|l|}{ Autobiographical memory } \\
\hline \multirow[t]{2}{*}{ Episodic details, periods 1-4 } & $r^{b}$ & 0.285 & 0.223 & 0.308 & 0.261 & 0.242 & 0.205 \\
\hline & $p$ & 0.052 & 0.133 & 0.035 & 0.076 & 0.101 & 0.166 \\
\hline \multirow[t]{2}{*}{ Episodic details, periods 1-2 } & $r$ & 0.251 & 0.161 & 0.273 & 0.229 & 0.201 & 0.133 \\
\hline & $p$ & 0.089 & 0.279 & 0.064 & 0.121 & 0.177 & 0.374 \\
\hline \multirow[t]{2}{*}{ Episodic details, periods $3-4$} & $r$ & 0.269 & 0.244 & 0.289 & 0.247 & 0.241 & 0.241 \\
\hline & $p$ & 0.068 & 0.098 & 0.049 & 0.093 & 0.102 & 0.103 \\
\hline \multirow[t]{2}{*}{ Semantic, periods 1-4 } & $r$ & 0.296 & 0.252 & 0.307 & 0.281 & 0.252 & 0.246 \\
\hline & $p$ & 0.043 & 0.088 & 0.036 & 0.056 & 0.087 & 0.096 \\
\hline \multirow[t]{2}{*}{ Semantic, periods 1-2 } & $r$ & 0.250 & 0.218 & 0.293 & 0.214 & 0.228 & 0.206 \\
\hline & $p$ & 0.090 & 0.142 & 0.046 & 0.149 & 0.123 & 0.164 \\
\hline \multirow[t]{2}{*}{ Semantic, periods 3-4 } & $r$ & 0.280 & 0.229 & 0.231 & 0.305 & 0.212 & 0.235 \\
\hline & $p$ & 0.057 & 0.122 & 0.119 & 0.037 & 0.152 & 0.113 \\
\hline
\end{tabular}

${ }^{a}$ Controlled for years of education.

${ }^{b}$ Pearson product-moment correlation coefficient (two-tailed) $p \leq 0.05, d f=45$. 
Table 6 | Partial correlations ${ }^{\mathrm{a}}$ between hippocampal volume and autobiographical memory in the healthy control group.

\begin{tabular}{|c|c|c|c|c|c|c|c|}
\hline Hippocampus & & Left & Right & Left anterior & Left posterior & Right anterior & Right posterior \\
\hline \multicolumn{8}{|l|}{ Autobiographical memory } \\
\hline Episodic details, periods $1-4$ & $r^{b}$ & 0.289 & 0.331 & 0.305 & 0.250 & 0.315 & 0.314 \\
\hline \multirow[t]{2}{*}{ Episodic details, periods $1-2$} & $r$ & 0.183 & 0.174 & 0.210 & 0.141 & 0.214 & 0.124 \\
\hline & $p$ & 0.440 & 0.464 & 0.374 & 0.552 & 0.366 & 0.602 \\
\hline \multirow[t]{2}{*}{ Semantic, periods $1-4$} & $r$ & 0.491 & 0.393 & 0.455 & 0.488 & 0.394 & 0.357 \\
\hline & $p$ & 0.028 & 0.087 & 0.044 & 0.029 & 0.086 & 0.123 \\
\hline \multirow[t]{2}{*}{ Semantic, periods $1-2$} & $r$ & 0.567 & 0.426 & 0.529 & 0.560 & 0.430 & 0.384 \\
\hline & $p$ & 0.009 & 0.061 & 0.017 & 0.010 & 0.058 & 0.095 \\
\hline Semantic, periods $3-4$ & $r$ & 0.222 & 0.235 & 0.200 & 0.227 & 0.229 & 0.218 \\
\hline
\end{tabular}

${ }^{a}$ Controlled for years of education.

${ }^{b}$ Pearson product-moment correlation coefficient (two-tailed) $p \leq 0.05, d f=18$.

Table 7 | Partial correlations ${ }^{a}$ between hippocampal volume and neuropsychological parameters in the patient group

\begin{tabular}{|c|c|c|c|c|c|c|c|}
\hline Hippocampus & & Left & Right & Left anterior & Left posterior & Right anterior & Right posterior \\
\hline \multicolumn{8}{|l|}{ Neuropsychology } \\
\hline Logical memory I & $r^{b}$ & 0.201 & 0.330 & 0.223 & 0.180 & 0.344 & 0.314 \\
\hline \multirow[t]{2}{*}{ Logical memory II } & $r$ & 0.155 & 0.294 & 0.194 & 0.124 & 0.321 & 0.271 \\
\hline & $p$ & 0.297 & 0.045 & 0.192 & 0.405 & 0.028 & 0.066 \\
\hline \multirow[t]{2}{*}{ Digit span backward } & $r$ & 0.260 & 0.291 & 0.319 & 0.213 & 0.325 & 0.264 \\
\hline & $p$ & 0.077 & 0.047 & 0.029 & 0.151 & 0.026 & 0.073 \\
\hline \multirow[t]{2}{*}{ Trail making test $A$} & $r$ & -0.181 & -0.141 & -0.193 & -0.167 & -0.142 & -0.137 \\
\hline & $p$ & 0.224 & 0.345 & 0.193 & 0.262 & 0.341 & 0.359 \\
\hline
\end{tabular}

${ }^{a}$ Controlled for years of education.

${ }^{b}$ Pearson product-moment correlation coefficient (two-tailed) $p \leq 0.05, d f=45$.

${ }^{c}$ Reduced $N$ in groups: 23 older patients, 20 younger patients.

${ }^{d}$ Product-moment correlation coefficient (two-tailed) $p \leq 0.05, d f=40$.

which is also detectable albeit to a lesser extent in younger patients with a chronic course of the disease; (2) AM performance for recent episodic details is significantly reduced in older and younger patients in contrast to healthy control subjects; neuropsychological deficits of the patients, i.e., verbal memory and executive functions, seem to deteriorate in the course of the disease; (3) hippocampal volume is significantly correlated with episodic and semantic AM, with different correlation patterns in patients and healthy controls; (4) only in the patient group, significant correlations between hippocampal volume and verbal memory, working memory, and executive functions arose.

\section{CLINICAL CHARACTERISTICS}

Most of the older patients were - in contrast to the younger patients - chronically hospitalized and therefore in a more remitted phase of the disorder. The significantly higher doses of $\mathrm{CPZ}$ equivalents in the younger patient group can therefore be explained by higher psychiatric symptom severity (BPRS sumscore) in this group, due to a shorter interval since last acute phase. Moreover, reduced CPZ equivalents in the older patient group can additionally be explained by age-related pharmacokinetic and pharmacodynamic changes (63-65). Considering the chronic course of the disease in our patient samples, 
predominant negative symptoms in both patient groups were expected.

\section{HIPPOCAMPAL VOLUME}

As expected, significant hippocampal volume alterations were evident between the groups, i. e., left and right hippocampal volumes were reduced in the older patients in comparison to the healthy subjects. These volumetric reductions of $9-14 \%$ are in line with previous studies, which focused on older patients with a duration of the disease of 25-30 years $(22,26,27)$. Corresponding to the results of Weiss et al. (22), we did not find a selective volumetric reduction along the anterior-posterior hippocampal axis. Similarly, the older patients' left and right hippocampal volumes were significantly reduced in comparison to the younger patient group. These results may reflect normal age-related brain changes on the one hand (66-68) and disease-related processes on the other hand $(69,70)$. For example, in a review of 11 longitudinal studies, the authors reported progressive cerebral changes (especially in frontal and temporal areas) in patients with chronic schizophrenia with a volume reduction of $-0.5 \%$ /year, which was more than twice the tissue decrease in healthy subjects $(-0.2 \% /$ year $)(71)$.

Hippocampal atrophy early in the disease process was previously described $(72,73)$, and is indirectly supported by the present findings, which show similar hippocampal volumes in younger patients and healthy subjects, which were 20 years older on average. Likewise, Chakos et al. (74) reported a significant reduction of hippocampal volume in younger $(24.9 \pm 8.8$ years of age $)$ and older patients ( $37.1 \pm 11.8$ years of age) in comparison to healthy controls, an effect which was more pronounced in the older patient group.

In our patient group, no significant interactions arose between hippocampal volume and CPZ-equivalents, sumscores of psychopathology, or duration of illness. Nevertheless, potential effects of especially typical antipsychotic medication on brain structure have to be considered, particularly in samples of patients with chronic schizophrenia as in our study, and may primarily affect basal ganglia volume (75-77). Although not all patients in the present study were exclusively treated with atypical antipsychotics, it should be noted that no extrapyramidal side-effects such as tardive dyskinesia could be observed. Recently, Ho et al. (78) reported in a longitudinal study with 211 first-episode patients a significant effect of antipsychotic medication on brain volume while controlling for severity of psychopathology, duration of follow-up, and substance abuse. Gray matter volume reduction in multiple cerebral areas was associated with higher doses independent of type of medication. However, no significant effects of antipsychotic type $(22,28,7980)$, duration of treatment (10), or dosage of medication $(10,81-84)$ on hippocampal volume were detected in patients with first-episode or chronic schizophrenia. Moreover, treatment with atypical antipsychotics was associated with larger hippocampal volumes than treatment with typical antipsychotics $(74,85)$. Longitudinally, the cumulative intake of atypical antipsychotic medication was related to a smaller hippocampal decrease in a sample of patients with chronic schizophrenia. This effect was - trend level only - reversed for typical medication (86).

In agreement with the present results (26) found, no significant correlations between hippocampal volume and duration of illness or severity of psychopathology (BRPS, SAPS, SANS) in a sample of middle-aged patients with chronic schizophrenia [see also Ref. (87)]. Other studies reported consistently with our findings no significant associations between hippocampal volume and illness duration $(11,82,88,89)$. Positive correlations between severity of psychopathology and right hippocampal volume were previously described (82), though there are also negative findings (28, 83 ). While positive symptoms seem to be related to hippocampus (90-92), in our patient samples negative symptoms were predominating.

\section{AUTOBIOGRAPHICAL MEMORY AND NEUROPSYCHOLOGICAL PERFORMANCE}

As hypothesized, AM performance was reduced in the older patients in comparison to the healthy control group. These differences applied for episodic and semantic autobiographical memories as well. Regarding different lifetime periods, significant impairments of the older patients were found with respect to recent episodic and remote semantic memories. In case of recent episodic memories also, the younger patient group was impaired in contrast to the even older healthy control group. A main effect of period indicates better memory performance for recent than remote autobiographical memories. The interaction group $\times$ period shows a tendency for episodic AM impairment in the patients especially for periods after onset of the disease.

The assessment of AM without temporal limitation and the differentiated profiles of episodic and semantic memories rule out confounding effects like reduced cognitive capacities, e. g., information processing speed or reduced motivation in our patient groups [cf. (31)]. The potential impact of confabulations (93) is considerably weakened by the fact that mnestic deficits were clearly evident in the autobiographical interview. Previous studies on AM in patients with schizophrenia found no evidence of false memories or confabulations $(32,94)$. Studies investigating susceptibility to false memories in patients with schizophrenia did not report elevated false recognition errors or intrusions (95-98). Concerning the truthfulness of the reported autobiographical memories, an additional interviewing of relatives is difficult not only in terms of practicability but also reduces the eligible episodic memories to shared experiences. Moreover, episodic autobiographical memories reflect subjective impressions, so the personal meaning of an event can nonetheless be accurate (30).

Our results are consistent with previous studies showing diminished episodic and semantic AM in younger patients with chronic schizophrenia, with reduced specificity, and detail of the reported autobiographical episodes, recency effect, and memory deficits especially from the time of illness onset $(29,30,31,33,94)$. In supplementing and extending our previous results (99), the younger patients remembered fewer recent episodic details than the healthy control group, while there was no significant difference between the patient groups. When interpreting these results, it has to be considered that the younger patients have a shorter time interval to autobiographical events from different lifetime periods due to their lower age, which emphasizes the reported deficits.

No significant correlations arose between sumscores of episodic and semantic AM and duration of illness or CPZ-equivalents, 
which corresponds to previous studies $(30,94)$. In accordance with findings from Corcoran and Frith (100) and Harrison and Fowler (101), the episodic sumscore was inversely correlated with SANS and AES scores; however, relationships with psychiatric symptoms were not consistently reported (94).

Negative symptoms are associated with frontal-executive processes $(102,103)$, which can be one possible explanation for the AM impairment given a sample of patients with predominantly negative symptoms (cf. impaired executive functions in our patient groups, discussed below). Similarly, executive functions like coordination and organization of information are among the best predictors for deficits of long-term memory in patients with schizophrenia (104). Likewise, in patients with depression, a positive association between specificity of AM and central executive processes of working memory was described (105); similar findings apply to healthy older adults (106).

Autobiographical specificity has also been discussed in light of context memory $(105,107)$, which is impaired in patients with schizophrenia (108). The reduced ability to combine contextual cues of events together (e. g., source, time) to form a coherent memory representation results in a more fractionated recollection of those events and in reduced autonoetic consciousness (109). Similarly, meta-analytic findings indicate a significant more pronounced deficit in associative recognition (intact vs. rearranged pairings of item with item/source/temporal order - therefore depending on conscious recollection) relative to item recognition (old/new judgment) in patients with schizophrenia (110). Therefore, AM deficits in schizophrenia are not only characterized by reduced specificity but also by reduced conscious recollection (32). In this respect, the critical role of the hippocampus for recollection rather than familiarity was emphasized by Yonelinas (111) and Eichenbaum et al. (112).

As expected, the older patients showed a significantly reduced performance in comparison to the healthy control subjects in all additional neuropsychological parameters with exception of short-term and working memory.

Dysfunction of verbal declarative memory is a very robust empirical finding in schizophrenia $(3,4,113)$ and one of the strongest predictors of functional outcome (114). Other cognitive parameters as attention deficits or symptom fluctuations cannot fully explain the extent of verbal declarative memory deficits in schizophrenia $(3,115)$.

Pronounced impairments in executive functions are among the most consistently reported cognitive deficits in schizophrenia and affect - together with reduced processing speed - memory performance $(4,113,116-118)$.

The BFFT was applied to examine remote semantic memory, $\mathrm{i}$. e., context-free knowledge without personal relevance in contrast to autobiographical episodic and semantic memory. Corresponding to our results, deficits in identifying and naming famous faces were documented in patients with chronic schizophrenia $(119,120)$.

In contrast to deficits of recent episodic AM, which were not significantly different between the two patient groups, the younger patients outperformed the older patients as expected in a range of neuropsychological parameters including verbal memory, processing speed, and executive functions. In case of verbal memory and executive functions, the largest group differences were evident, with the younger patients showing marked deficits even in comparison to the older healthy controls. The differentiating profiles of AM and additional neuropsychological domains between the three groups examined emphasize once again the exceptional position of AM as probably the most complex memory system (121).

Logical memory and TMT B performance of the older patient group in our study are comparable with that of patients with mild cognitive impairment $(122,123)$. Given hippocampal changes in patients with schizophrenia - which even can show a similar amount of volume reduction as in patients with Alzheimer's disease (28) - these results raise the question of neurodegenerative processes in schizophrenia (124). However, cognitive profiles of patients with schizophrenia and Alzheimer's disease are different in spite of pronounced impairments in both groups (125-128). Additionally, a meta-analysis (129) and several subsequent studies did not report an Alzheimer's disease-like neuropathology in schizophrenia (130-135). However, the lacking evidence of typical neurodegeneration in schizophrenia does not exclude progressive components like changes in neuropsychological functioning or brain volume (124). Furthermore, as in our sample, age-related cognitive deterioration can be suggested in older, institutionalized individuals with chronic schizophrenia (136). In this context, it has to be mentioned that physical illnesses like the metabolic syndrome, which are associated with cognitive deficits and increase with rising age (137), are more prevalent among patients with schizophrenia $(138,139)$.

A similar pattern of cognitive deterioration with increasing chronicity of the disease as in our sample was observed in a study with 122 patients with chronic schizophrenia (140). As in our results, among others, especially verbal memory was affected by duration of illness, therefore, suggesting a progressive deteriorating course, while other neurocognitive domains remain rather stable. These results are well in line with findings of a recent meta-analysis, which reports cross-sectionally large and heterogeneous deficits in global cognition $(d=-1.19)$ and specific neuropsychological domains as language, memory, and executive functions $(d=-0.7$ to -1.14$)$ in older individuals with chronic schizophrenia (141). According to the results presented here, advanced age and living institutionalized were associated with more severe impairments; antipsychotic dose was not a significant moderator.

Consistent with results of meta-analyses and reviews, only non-significant correlations between additional neuropsychological parameters and CPZ-equivalents arose $(3,115,116)$. Other studies reported evidence of beneficial impact of atypical (142144) and typical (145-147) antipsychotics on cognitive abilities in patients with schizophrenia.

In our study, negative symptoms (SANS sumscore) were significantly correlated with diminished performance of Logical Memory, TMT A and B, and BFFT. This also applies to the extent of apathy, while similar associations of positive symptoms or BPRS sumscore with neuropsychological performance did not appear. In accordance with our results, associations between negative symptoms and memory or executive functions were repeatedly reported $(3,115,116,148)$. 


\section{CORRELATIONS BETWEEN HIPPOCAMPAL VOLUME AND AUTOBIOGRAPHICAL MEMORY}

Significant correlations between AM and hippocampal volume arose in the patient and control group as expected. Episodic and semantic AM was associated with left hippocampus in the patient group. Especially, recent episodic memories were correlated with hippocampus; however, in case of semantic memories these correlations were significant for both recent and remote memories. In contrast, in the control group the correlations were restricted to remote semantic AM. This pattern can only partly be explained by the standard model of consolidation, which postulates a timelimited role of hippocampus in the formation and retention of declarative memory $(36,37,149)$. This is true for episodic AM in the patient group; however, in case of semantic AM there was no temporal gradient; hence also the multiple-trace-theory cannot account for these results $(38,40)$. According to this view, maintenance and re-experiencing of vivid and detailed events depend on hippocampal formation as long as they exist, whereas semantic, that is context-free memories and schematic representations, benefit from hippocampal contribution before they are retrieved independent of this structure.

In case of the present study, the frequency of retrieval of the semantic information addressed in our interview and especially the frequency of retrieval of recent semantic knowledge may be reduced in patients with schizophrenia due to diminished necessity. This is of particular importance as more seldomly retrieved memories remain dependent on hippocampus no matter how old they are $(150,151)$. This assumption may also apply to the correlation between remote semantic AM and hippocampus in the control group. In healthy subjects, questions relating to former addresses or names of teachers possibly refer to facts more seldomly retrieved than episodic memories like the own wedding. It might be argued that patients with chronic schizophrenia experienced, due to their illness, fewer "normative" autobiographical events like wedding which could be reported. However, apart from that, all episodes were scored according to the remembered details. In contrast, one might expect that healthy persons have frequently reported such common events, which therefore are semantizised, and exist independent of hippocampal formation, as our results indicate (152).

To test the influence of retrieval frequency of remote semantic memory, we used the BFFT. Participants had to identify famous faces known from the media. Results show only non-significant associations between BFFT-performance and hippocampal volume in both groups. Additional indications for the assumption that frequently retrieved remote semantic memories are rather independent of hippocampus came from previous studies (153155). In this context, the personal relevance of semantic information has to be considered as a potential factor that may result in a performance advantage $(156,157)$. However, the autobiographical significance of the stimuli used in the BFFT was not explicitly requested as the recognition was focused on.

Another objection also concerns the retrieval frequency of remote semantic AM, which as a matter of fact should have been frequently retrieved and therefore should exist independent of hippocampus. Leyhe et al. (151) argue that information frequently retrieved in the past has to be consolidated by the hippocampus; once again, when this information had not been used for a time and thus the cortical network is weakened again. This may also apply to our findings of significant associations between hippocampal volume and remote semantic AM in patients and controls. Similarly, in functional imaging studies hippocampal activity (via PET, functional MRI) for remote autobiographical memories was more pronounced or more widespread than for recent ones (158-160).

Our results show that left in comparison to right hippocampus is significantly correlated with AM. A left-lateralized pattern of medial temporal lobe activation (via PET, functional MRI) was also frequently reported in functional imaging studies of AM (161, 162), which is explained by stimulus modality, with the left hippocampus being more involved in retrieval of contextual details of episodic memory and the right hippocampus in spatial memory (163-168). In addition, lesion studies show that damage to the left medial temporal lobe results more frequently in episodic memory impairment than right lateralized damage (169).

In the present study, mainly, the anterior hippocampus was significantly correlated with AM performance in the patient group [see also Ref. $(170,171)$ ], while in the control group a specific topographical pattern of hippocampal involvement did not emerge. Similarly, significant correlations of anterior and posterior hippocampus with memory performance were reported in patients with schizophrenia and healthy subjects $(15,21)$. The assumption of a rostrocaudal distribution of hippocampal activity (via PET) during encoding and retrieval as described in the HIPERmodel (23) was mitigated by findings of anterior and posterior hippocampal activation (via PET, functional MRI, event-related potentials by hippocampal electrodes) during both encoding and retrieval, respectively (172-174).

While interpreting the correlative results of AM in the present study, it should be noted that - in the face of the existing age variance within the patient group - the time interval relative to the lifetime periods examined varies in older and younger patients. Such influences can not be fully excluded as age during encoding and retrieval of information affect hippocampal involvement as does the oldness of the to-be-retrieved episode (175-179).

\section{CORRELATIONS BETWEEN HIPPOCAMPAL VOLUME AND NEUROPSYCHOLOGY}

According to our assumption among the additional neuropsychological parameters, we found verbal memory and working memory to be correlated primarily with right hippocampus. Executive functions, assessed by TMT B, showed significant negative associations with left and right hippocampal volume, indicating the smaller the hippocampus the more time is needed for alternating between numbers and letters. These associations only applied to the patient group.

A variety of studies investigating the relationship between neurocognition and hippocampal formation in schizophrenia has reported associations with verbal memory and executive functions $(24,25)$ : Consistent with our results, positive correlations of hippocampal volume with parameters of verbal memory (assessed via Wechsler Memory Scale) were reported in patients with chronic schizophrenia and healthy subjects $(88,89)$. The present associations between right hippocampal volume and immediate and delayed verbal recall also correspond to previous findings 
$(27,89,180)$. Sachdev et al. (27) found reduced verbal and visual memory performance and impaired executive functions in 20 elderly patients $(64.4 \pm 10.6$ years of age) with chronic schizophrenia (duration of illness: $29.7 \pm 16.6$ years) in comparison to a somewhat older healthy control group ( $72.7 \pm 6.7$ years of age). Only in the patient group, right hippocampal volume was significantly correlated to verbal and visual memory. However, these results are frequently based on composite neuropsychological test scores or neuropsychological data reduced via factor analysis (27, $88,89,180,181$ ).

In the present study, executive impairments were significantly inversely correlated with left and right hippocampal volumes in the patient group. Likewise, in the above cited study by Sachdev et al. (27), frontal executive functions were significantly correlated with bilateral hippocampal volume, which applied only to the patient group. Executive functions, also measured, interalia, using the TMT B, were significantly correlated with anterior hippocampal volume in patients with first-episode (182) and chronic schizophrenia (14). These findings implicate that a possible neurodevelopmental hippocampal abnormality changes prefrontal structures or connections in adulthood (183-185), which may well explain the associations of hippocampus with executive functions $(27,182,186)$.

In our study, working memory, assessed by the Digit Span backward, was significantly associated with bilateral hippocampal volume in the patient group. Similar results were reported in a VBM-study with impaired performance during the spatial span backwards being correlated with reduced gray matter volume of hippocampus (187). Structural and functional correlates (via functional MRI) of working memory were examined in a group of 154 individuals with schizophrenia, their siblings, and healthy controls. Results show positive correlations of hippocampal volume with working memory activity in dorsal anterior cingulate cortex and left inferior frontal gyrus, thus indicating long-distance structural-functional relationships (188).

To sum up, we found pronounced deficits of AM and additional neuropsychological parameters along with hippocampal volume reduction in a sample of older patients with chronic schizophrenia. While AM impairments seem to be relatively stable, other neuropsychological functions deteriorate cross-sectionally, which points at the complexity of AM. Our correlational findings extend previous results (99) and underline the relevance of volumetric hippocampal alterations in patients with chronic schizophrenia. However, a further examination of volumetric and neuropsychological changes in the course of the disease requires longitudinal data; therefore, a follow-up analysis is planned. Considering recent imaging findings of white matter abnormalities in schizophrenia potentially disconnecting the hippocampus from other structures [e. g., Ref. $(185,189)]$, further studies should also refer to the role of white matter in schizophrenia, using functional and structural imaging as well as neuropsychological investigations (190-192).

\section{AUTHOR CONTRIBUTIONS}

$\mathrm{CH}$ performed data collection, image processing, statistical analyses, and wrote the manuscript. ML and LS performed data collection, supported statistical analysis, and interpretation of data. ME supervised MRI procedures and clinical evaluation of the MRIs. PT, IF, and LK supported MRI data analysis and interpretation of data. US was involved in designing the study and interpretation of data. JS supervised study design and clinical assessments, supported data collection, and contributed to the interpretation of the results. All authors participated in critical revising and final approval of the manuscript, and agree to be accountable for all aspects of the work.

\section{ACKNOWLEDGMENTS}

This study was supported by the Dietmar-Hopp-Foundation, St. Leon-Rot, Germany. The authors are grateful to Kirk I. Erickson for his valuable assistance. We acknowledge the financial support of the Deutsche Forschungsgemeinschaft and Ruprecht-KarlsUniversität Heidelberg within the funding programme Open Access Publishing.

\section{REFERENCES}

1. Fornito A, Yücel M, Patti J, Wood SJ, Pantelis C. Mapping grey matter reductions in schizophrenia: an anatomical likelihood estimation analysis of voxel-based morphometry studies. Schizophr Res (2009) 108:104-13. doi:10.1016/j.schres. 2008.12.011

2. Adriano F, Caltagirone C, Spalletta G. Hippocampal volume reduction in firstepisode and chronic schizophrenia: a review and meta-analysis. Neuroscientist (2012) 18:180-200. doi:10.1177/1073858410395147

3. Cirillo MA, Seidman LJ. Verbal declarative memory dysfunction in schizophrenia: from clinical assessment to genetics and brain mechanisms. Neuropsychol Rev (2003) 13:43-77. doi:10.1023/A:1023870821631

4. Dickinson D, Ramsey ME, Gold JM. Overlooking the obvious: a meta-analytic comparison of digit symbol coding tasks and other cognitive measures in schizophrenia. Arch Gen Psychiatry (2007) 64:532-42. doi:10.1001/archpsyc. 64.5.532

5. Mesholam-Gately RI, Giuliano AJ, Goff KP, Faraone SV, Seidman LJ. Neurocognition in first-episode schizophrenia: a meta-analytic review. Neuropsychology (2009) 23:315-36. doi:10.1037/a0014708

6. Cohen CI, Cohen GD, Blank K, Gaitz C, Katz IR, Leuchter A, et al. Schizophrenia and older adults. An overview: directions for research and policy. Am J Geriatr Psychiatry (2000) 8:19-28. doi:10.1097/00019442-200002000-00003

7. Cohen CI, Vahia I, Reyes P, Diwan S, Bankole AO, Palekar N, et al. Focus on geriatric psychiatry: schizophrenia in later life: clinical symptoms and social well-being. Psychiatr Serv (2008) 59:232-4. doi:10.1176/appi.ps.59.3.232

8. Nelson MD, Saykin AJ, Flashman LA, Riordan HJ. Hippocampal volume reduction in schizophrenia as assessed by magnetic resonance imaging: a metaanalytic study. Arch Gen Psychiatry (1998) 55:433-40. doi:10.1001/archpsyc. 55.5.433

9. Wright IC, Rabe-Hesketh S, Woodruff PW, David AS, Murray RM, Bullmore ET. Meta-analysis of regional brain volumes in schizophrenia. Am J Psychiatry (2000) 157:16-25. doi:10.1176/ajp.157.1.16

10. Lieberman JA, Chakos M, Wu H, Alvir J, Hoffman E, Robinson D, et al. Longitudinal study of brain morphology in first episode schizophrenia. Biol Psychiatry (2001) 49:487-99. doi:10.1016/S0006-3223(01)01067-8

11. Pegues MP, Rogers LJ, Amend D, Vinogradov S, Deicken RF. Anterior hippocampal volume reduction in male patients with schizophrenia. Schizophr Res (2003) 60:105-15. doi:10.1016/s0920-9964(02)00288-8

12. Szeszko PR, Goldberg E, Gunduz-Bruce H, Ashtari M, Robinson D, Malhotra AK, et al. Smaller anterior hippocampal formation volume in antipsychoticnaive patients with first-episode schizophrenia. Am J Psychiatry (2003) 160:2190-7. doi:10.1176/appi.ajp.160.12.2190

13. Narr KL, Thompson PM, Szeszko P, Robinson D, Jang S, Woods RP, et al. Regional specificity of hippocampal volume reductions in first-episode schizophrenia. Neuroimage (2004) 21:1563-75. doi:10.1016/j.neuroimage. 2003.11.011

14. Schobel SA, Kelly MA, Corcoran CM, Van Heertum K, Seckinger R, Goetz R, et al. Anterior hippocampal and orbitofrontal cortical structural brain abnormalities in association with cognitive deficits in schizophrenia. Schizophr Res (2009) 114:110-8. doi:10.1016/j.schres.2009.07.016 
15. Thoma RJ, Monnig M, Hanlon FM, Miller GA, Petropoulos H, Mayer AR, et al. Hippocampus volume and episodic memory in schizophrenia. J Int Neuropsychol Soc (2009) 15:182-95. doi:10.1017/S1355617709090225

16. Becker T, Elmer K, Schneider F, Schneider M. Confirmation of reduced temporal limbic structure volume on magnetic resonance imaging in male patients with schizophrenia. Psychiatry Res (1996) 67:135-43. doi:10.1016/ 0925-4927(96)03002-8

17. Hirayasu Y, Shenton ME, Salisbury DF, Dickey CC, Fischer IA, Mazzoni P, et al. Lower left temporal lobe MRI volumes in patients with first-episode schizophrenia compared with psychotic patients with first-episode affective disorder and normal subjects. Am J Psychiatry (1998) 155:1384-91. doi:10.1176/ajp.155.10.1384

18. Narr KL, Thompson PM, Sharma T, Moussai J, Blanton R, Anvar B, et al. Three-dimensional mapping of temporo-limbic regions and the lateral ventricles in schizophrenia: gender effects. Biol Psychiatry (2001) 50:84-97. doi:10.1016/s0006-3223(00)01120-3

19. Velakoulis D, Stuart GW, Wood SJ, Smith DJ, Brewer WJ, Desmond P, et al. Selective bilateral hippocampal volume loss in chronic schizophrenia. Biol Psychiatry (2001) 50:531-9. doi:10.1016/s0006-3223(01)01121-0

20. Yamasue H, Iwanami A, Hirayasu Y, Yamada H, Abe O, Kuroki N, et al. Localized volume reduction in prefrontal, temporolimbic, and paralimbic regions in schizophrenia: An MRI parcellation study. Psychiatry Res (2004) 131:195-207. doi:10.1016/j.pscychresns.2004.05.004

21. Rametti G, Segarra N, Junque C, Bargallo N, Caldu X, Ibarretxe N, et al. Left posterior hippocampal density reduction using VBM and stereological MRI procedures in schizophrenia. Schizophr Res (2007) 96:62-71. doi:10.1016/j. schres.2007.04.034

22. Weiss AP, Dewitt I, Goff D, Ditman T, Heckers S. Anterior and posterior hippocampal volumes in schizophrenia. Schizophr Res (2005) 73:103-12. doi:10.1016/j.schres.2004.05.018

23. Lepage M, Habib R, Tulving E. Hippocampal PET activations of memory encoding and retrieval: the HIPER model. Hippocampus (1998) 8:313-22. doi:10.1002/(SICI)1098-1063(1998)8:4<313::AID-HIPO1>3.0.CO;2-I

24. Antonova E, Sharma T, Morris R, Kumari V. The relationship between brain structure and neurocognition in schizophrenia: a selective review. Schizophr Res (2004) 70:117-45. doi:10.1016/j.schres.2003.12.002

25. Crespo-Facorro B, Barbadillo L, Pelayo-Teran JM, Rodriguez-Sanchez JM. Neuropsychological functioning and brain structure in schizophrenia. Int Rev Psychiatr (2007) 19:325-36. doi:10.1080/09540260701486647

26. Altshuler LL, Bartzokis G, Grieder T, Curran J, Jimenez T, Leight K, et al. An MRI study of temporal lobe structures in men with bipolar disorder or schizophrenia. Biol Psychiatry (2000) 48:147-62. doi:10.1016/S0006-3223(00)00836-2

27. Sachdev P, Brodaty H, Cheang D, Cathcart S. Hippocampus and amygdala volumes in elderly schizophrenic patients as assessed by magnetic resonance imaging. Psychiatry Clin Neurosci (2000) 54:105-12. doi:10.1046/j.1440-1819. 2000.00644.x

28. Prestia A, Boccardi M, Galluzzi S, Cavedo E, Adorni A, Soricelli A, et al. Hippocampal and amygdalar volume changes in elderly patients with Alzheimer's disease and schizophrenia. Psychiatry Res (2011) 192:77-83. doi:10.1016/j. pscychresns.2010.12.015

29. Feinstein A, Goldberg TE, Nowlin B, Weinberger DR. Types and characteristics of remote memory impairment in schizophrenia. Schizophr Res (1998) 30:155-63. doi:10.1016/S0920-9964(97)00129-1

30. Elvevåg B, Kerbs KM, Malley JD, Seeley E, Goldberg TE. Autobiographical memory in schizophrenia: an examination of the distribution of memories. Neuropsychology (2003) 17:402-9. doi:10.1037/0894-4105.17.3.402

31. Riutort M, Cuervo C, Danion JM, Peretti CS, Salame P. Reduced levels of specific autobiographical memories in schizophrenia. Psychiatry Res (2003) 117:35-45. doi:10.1016/S0165-1781(02)00317-7

32. Danion JM, Cuervo C, Piolino P, Huron C, Riutort M, Peretti CS, et al. Conscious recollection in autobiographical memory: an investigation in schizophrenia. Conscious Cogn (2005) 14:535-47. doi:10.1016/j.concog.2005.01.005

33. Wood N, Brewin CR, Mcleod HJ. Autobiographical memory deficits in schizophrenia. Cogn Emot (2006) 20:536-47. doi:10.1080/02699930500342472

34. Herold CJ, Lässer MM, Schmid LA, Seidl U, Kong L, Fellhauer I, et al. Hippocampal volume reduction and autobiographical memory deficits in chronic schizophrenia. Psychiatry Res (2013) 211:189-94. doi:10.1016/j.pscychresns. 2012.04.002
35. Squire LR. Memory and the hippocampus: a synthesis from findings with rats, monkeys, and humans. Psychol Rev (1992) 99:195-231. doi:10.1037/0033295X.99.2.195

36. Dudai Y. The neurobiology of consolidations, or, how stable is the engram? Annu Rev Psychol (2004) 55:51-86. doi:10.1146/annurev.psych.55.090902. 142050

37. Squire LR, Bayley PJ. The neuroscience of remote memory. Curr Opin Neurobiol (2007) 17:185-96. doi:10.1016/j.conb.2007.02.006

38. Nadel L, Moscovitch M. Memory consolidation, retrograde amnesia and the hippocampal complex. Curr Opin Neurobiol (1997) 7:217-27. doi:10.1016/ S0959-4388(97)80010-4

39. Moscovitch M, Rosenbaum RS, Gilboa A, Addis DR, Westmacott R, Grady C, et al. Functional neuroanatomy of remote episodic, semantic and spatial memory: a unified account based on multiple trace theory. J Anat (2005) 207:35-66. doi:10.1111/j.1469-7580.2005.00421.x

40. Moscovitch M, Nadel L, Winocur G, Gilboa A, Rosenbaum RS. The cognitive neuroscience of remote episodic, semantic and spatial memory. Curr Opin Neurobiol (2006) 16:179-90. doi:10.1016/j.conb.2006.03.013

41. Winocur G, Moscovitch M, Bontempi B. Memory formation and long-term retention in humans and animals: convergence towards a transformation account of hippocampal-neocortical interactions. Neuropsychologia (2010) 48:2339-56. doi:10.1016/j.neuropsychologia.2010.04.016

42. Winocur G, Moscovitch M. Memory transformation and systems consolidation. JInt Neuropsychol Soc (2011) 17:766-80. doi:10.1017/s1355617711000683

43. Saß H, Wittchen HU, Zaudig M, Houben I. Diagnostisches und Statistisches Manual Psychischer Störungen - Textrevision-DSM-IV-TR. Göttingen: Hogrefe (2003).

44. Andreasen NC. Scale for the Assessment of Positive Symptoms (SAPS). Iowa City: Department of Psychiatry, College of Medicine, University of Iowa (1984).

45. Andreasen NC. Scale for the Assessment of Negative Symptoms (SANS). Iowa City: Department of Psychiatry, University of Iowa College of Medicine (1984).

46. Overall JE, Gorham DR. The Brief Psychiatric Rating Scale. Psychol Rep (1962) 10:799-812. doi:10.2466/pr0.1962.10.3.799

47. Marin RS, Biedrzycki RC, Firinciogullari S. Reliability and validity of the Apathy Evaluation Scale. Psychiatry Res (1991) 38:143-62. doi:10.1016/0165-1781(91) 90040-V

48. Oldfield RC. The assessment and analysis of handedness: the Edinburgh inventory. Neuropsychologia (1971) 9:97-113. doi:10.1016/0028-3932(71)90067-4

49. Fast K, Fujiwara E, Schröder J, Markowitsch HJ. Erweitertes Autobiographisches Gedächtnisinventar (E-AGI). Frankfurt: Harcourt (2007).

50. Kopelman MD, Wilson BA, Baddeley AD. Autobiographical Memory Inventory. Bury St. Edmunds: Thames Valley Test Company (1990).

51. Ahlsdorf E. Differenzielle Untersuchungen zum Autobiographischen Gedächtnis. Hamburg: Verlag Dr. Kovač (2009).

52. Härting C, Markowitsch HJ, Neufeld H, Calabrese P, Deisinger K, Kessler J editors. Deutsche Adaptation der revidierten Fassung der Wechsler Memory Scale (WMS-R). Bern: Verlag Hans Huber (2000).

53. Reitan C. The Trail Making Test: Manual for Administration and Scoring. Tucson: The Reitan Neuropsychological Laboratory (1992).

54. Jänicke C. Die Entwicklung des Bielefelder Famous Faces Test (2001). Available from: http://systemische-organisationsberatung.com/Die\%20Entwicklung\% 20des\%20Bielefelder\%20Famous\%20Faces\%20Test.pdf

55. Smith SM, Jenkinson M, Woolrich MW, Beckmann CF, Behrens TE, JohansenBerg $\mathrm{H}$, et al. Advances in functional and structural MR image analysis and implementation as FSL. Neuroimage (2004) 23(Suppl 1):208-19. doi:10.1016/ j.neuroimage.2004.07.051

56. Woolrich MW, Jbabdi S, Patenaude B, Chappell M, Makni S, Behrens T, et al. Bayesian analysis of neuroimaging data in FSL. Neuroimage (2009) 45:173-86. doi:10.1016/j.neuroimage.2008.10.055

57. Patenaude B, Smith SM, Kennedy DN, Jenkinson M. A bayesian model of shape and appearance for subcortical brain segmentation. Neuroimage (2011) 56:907-22. doi:10.1016/j.neuroimage.2011.02.046

58. Erickson KI, Prakash RS, Voss MW, Chaddock L, Hu L, Morris KS, et al. Aerobic fitness is associated with hippocampal volume in elderly humans. Hippocampus (2009) 19:1030-9. doi:10.1002/hipo.20547

59. Erickson KI, Voss MW, Prakash RS, Basak C, Szabo A, Chaddock L, et al. Exercise training increases size of hippocampus and improves memory. Proc Nat Acad Sci U S A (2011) 108:3017-22. doi:10.1073/pnas.1015950108 
60. Greenhouse SW, Geisser S. On methods in the analysis of profile data. Psychometrika (1959) 24:95-112. doi:10.1007/BF02289823

61. Eckstein PP. Angewandte Statistik Mit SPSS. Wiesbaden: Gabler Verlag (2008).

62. Woods SW. Chlorpromazine equivalent doses for the newer atypical antipsychotics. J Clin Psychiatry (2003) 64:663-7. doi:10.4088/JCP.v64n0607

63. Sajatovic M, Madhusoodanan S, Buckley P. Schizophrenia in the elderly: guidelines for management. CNS Drugs (2000) 13:103-15. doi:10.2165/00023210200013020-00004

64. Mamo DC, Sweet RA, Chengappa KNR, Reddy RR, Jeste DV. The effect of age on the pharmacological management of ambulatory patients treated with depot neuroleptic medications for schizophrenia and related psychotic disorders. Int J Geriatr Psychiatry (2002) 17:1012-7. doi:10.1002/gps.740

65. Mintzer J, Targum SD. Psychosis in elderly patients: classification and pharmacotherapy. J Geriatr Psychiatry Neurol (2003) 16:199-206. doi:10.1177/ 0891988703258658

66. Raz N, Rodrigue KM, Head D, Kennedy KM, Acker JD. Differential aging of the medial temporal lobe: a study of a five-year change. Neurology (2004) 62:433-8. doi:10.1212/01.WNL.0000106466.09835.46

67. Raz N, Lindenberger U, Rodrigue KM, Kennedy KM, Head D, Williamson A, et al. Regional brain changes in aging healthy adults: general trends, individual differences and modifiers. Cereb Cortex (2005) 15:1679-89. doi:10.1093/ cercor/bhi044

68. Guimaraes RM, Schaufelberger MS, Santos LC, Duran FL, Menezes PR, Scazufca M, et al. Longitudinal brain volumetric changes during one year in non-elderly healthy adults: a voxel-based morphometry study. Braz J Med Biol Res (2012) 45:516-23. doi:10.1590/S0100-879X2012007500046

69. Okubo Y, Saijo T, Oda K. A review of MRI studies of progressive brain changes in schizophrenia. J Med Dent Sci (2001) 48:61-7.

70. Delisi LE. The concept of progressive brain change in schizophrenia: implications for understanding schizophrenia. Schizophr Bull (2008) 34:312-21. doi:10.1093/schbul/sbm164

71. Hulshoff Pol HE, Kahn RS. What happens after the first episode? A review of progressive brain changes in chronically ill patients with schizophrenia. Schizophr Bull (2008) 34:354-66. doi:10.1093/schbul/sbm168

72. Steen RG, Mull C, Mcclure R, Hamer RM, Lieberman JA. Brain volume in first-episode schizophrenia: systematic review and meta-analysis of magnetic resonance imaging studies. Br J Psychiatry (2006) 188:510-8. doi:10.1192/bjp. 188.6.510

73. Vita A, De Peri L, Silenzi C, Dieci M. Brain morphology in first-episode schizophrenia: a meta-analysis of quantitative magnetic resonance imaging studies. Schizophr Res (2006) 82:75-88. doi:10.1016/j.schres.2005.11.004

74. Chakos MH, Schobel SA, Gu H, Gerig G, Bradford D, Charles C, et al. Duration of illness and treatment effects on hippocampal volume in male patients with schizophrenia. Br J Psychiatry (2005) 186:26-31. doi:10.1192/bjp.186.1.26

75. Vita A, De Peri L. The effects of antipsychotic treatment on cerebral structure and function in schizophrenia. Int Rev Psychiatr (2007) 19:431-8. doi:10.1080/09540260701486332

76. Navari S, Dazzan P. Do antipsychotic drugs affect brain structure? A systematic and critical review of MRI findings. Psychol. Med (2009) 39:1763-77. doi:10.1017/s0033291709005315

77. Smieskova R, Fusar-Poli P, Allen P, Bendfeldt K, Stieglitz RD, Drewe J, et al. The effects of antipsychotics on the brain: what have we learnt from structural imaging of schizophrenia? - a systematic review. Curr Pharm Des (2009) 15:2535-49. doi:10.2174/138161209788957456

78. Ho BC, Andreasen NC, Ziebell S, Pierson R, Magnotta V. Long-term antipsychotic treatment and brain volumes: a longitudinal study of firstepisode schizophrenia. Arch Gen Psychiatry (2011) 68:128-37. doi:10.1001/ archgenpsychiatry.2010.199

79. Arango C, Breier A, Mcmahon R, Carpenter WT Jr, Buchanan RW. The relationship of clozapine and haloperidol treatment response to prefrontal, hippocampal, and caudate brain volumes. Am J Psychiatry (2003) 160:1421-7. doi:10.1176/appi.ajp.160.8.1421

80. Velakoulis D, Wood SJ, Wong MT, Mcgorry PD, Yung A, Phillips L, et al. Hippocampal and amygdala volumes according to psychosis stage and diagnosis: a magnetic resonance imaging study of chronic schizophrenia, first-episode psychosis, and ultra-high-risk individuals. Arch Gen Psychiatry (2006) 63:139-49. doi:10.1001/archpsyc.63.2.139

81. Velakoulis D, Pantelis C, Mcgorry PD, Dudgeon P, Brewer W, Cook M, et al. Hippocampal volume in first-episode psychoses and chronic schizophrenia: a high-resolution magnetic resonance imaging study. Arch Gen Psychiatry (1999) 56:133-41. doi:10.1001/archpsyc.56.2.133

82. Sim K, Dewitt I, Ditman T, Zalesak M, Greenhouse I, Goff D, et al. Hippocampal and parahippocampal volumes in schizophrenia: a structural MRI study. Schizophr Bull (2006) 32:332-40. doi:10.1093/schbul/sbj030

83. Exner C, Nehrkorn B, Martin V, Huber M, Shiratori K, Rief W. Sex-dependent hippocampal volume reductions in schizophrenia relate to episodic memory deficits. J Neuropsychiatry Clin Neurosci (2008) 20:227-30. doi:10.1176/appi. neuropsych.20.2.227

84. Irle E, Lange C, Ruhleder M, Exner C, Siemerkus J, Weniger G. Hippocampal size in women but not men with schizophrenia relates to disorder duration. Psychiatry Res (2011) 192:133-9. doi:10.1016/j.pscychresns.2010.12.009

85. Mcclure RK, Phillips I, Jazayerli R, Barnett A, Coppola R, Weinberger DR. Regional change in brain morphometry in schizophrenia associated with antipsychotic treatment. Psychiatry Res (2006) 148:121-32. doi:10.1016/j. pscychresns.2006.04.008

86. Koolschijn PCMP, Van Haren NEM, Cahn W, Schnack HG, Janssen J, Klumpers F, et al. Hippocampal volume change in schizophrenia. J Clin Psychiatry (2010) 71:737-44. doi:10.4088/JCP.08m04574yel

87. Whitworth AB, Honeder M, Kremser C, Kemmler G, Felber S, Hausmann A, et al. Hippocampal volume reduction in male schizophrenic patients. Schizophr Res (1998) 31:73-81. doi:10.1016/S0920-9964(98)00013-9

88. Gur RE, Turetsky BI, Cowell PE, Finkelman C, Maany V, Grossman RI, et al. Temporolimbic volume reductions in schizophrenia. Arch Gen Psychiatry (2000) 57:769-75. doi:10.1001/archpsyc.57.8.769

89. Kuroki N, Kubicki M, Nestor PG, Salisbury DF, Park H-J, Levitt JJ, et al. Fornix integrity and hippocampal volume in male schizophrenic patients. Biol Psychiatry (2006) 60:22-31. doi:10.1016/j.biopsych.2005.09.021

90. Goghari VM, Sponheim SR, Macdonald III. The functional neuroanatomy of symptom dimensions in schizophrenia: a qualitative and quantitative review of a persistent question. Neurosci Biobehav Rev (2010) 34:468-86. doi:10.1016/j.neubiorev.2009.09.004

91. Nenadic I, Sauer H, Gaser C. Distinct pattern of brain structural deficits in subsyndromes of schizophrenia delineated by psychopathology. Neuroimage (2010) 49:1153-60. doi:10.1016/j.neuroimage.2009.10.014

92. Jardri R, Pouchet A, Pins D, Thomas P. Cortical activations during auditory verbal hallucinations in schizophrenia: a coordinate-based meta-analysis. Am J Psychiatry (2011) 168:73-81. doi:10.1176/appi.ajp.2010.09101522

93. Schacter DL, Norman KA, Koutstaal W. The cognitive neuroscience of constructive memory. Annu Rev Psychol (1998) 49:289-318. doi:10.1146/annurev. psych.49.1.289

94. Neumann A, Blairy S, Lecompte D, Philippot P. Specificity deficit in the recollection of emotional memories in schizophrenia. Conscious Cogn (2007) 16:469-84. doi:10.1016/j.concog.2006.06.014

95. Huron C, Danion J-M. Impairment of constructive memory in schizophrenia. Int Clin Psychopharmacol (2002) 17:127-33. doi:10.1097/00004850200205000-00006

96. Elvevåg B, Fisher JE, Weickert TW, Weinberger DR, Goldberg TE. Lack of false recognition in schizophrenia: a consequence of poor memory? Neuropsychologia (2004) 42:546-54. doi:10.1016/j.neuropsychologia.2003.08.013

97. Moritz S, Woodward TS, Cuttler C, Whitman JC, Watson JM. False memories in schizophrenia. Neuropsychology (2004) 18:276-83. doi:10.1037/0894-4105. 18.2.276

98. Moritz S, Woodward TS, Rodriguez-Raecke R. Patients with schizophrenia do not produce more false memories than controls but are more confident in them. Psychol Med (2006) 36:659-67. doi:10.1017/s0033291706007252

99. Herold CJ. Autobiographisches Gedächtnis und Hippokampus bei chronisch schizophrenen Psychosen. Hamburg: Verlag Dr. Kovač (2013).

100. Corcoran R, Frith CD. Autobiographical memory and theory of mind: evidence of a relationship in schizophrenia. Psychol Med (2003) 33:897-905. doi:10.1017/S0033291703007529

101. Harrison CL, Fowler D. Negative symptoms, trauma, and autobiographical memory: an investigation of individuals recovering from psychosis. J Nerv Ment Dis (2004) 192:745-53. doi:10.1097/01.nmd.0000144693.12282.11

102. Dibben CR, Rice C, Laws K, Mckenna PJ. Is executive impairment associated with schizophrenic syndromes? A meta-analysis. Psychol Med (2009) 39:381-92. doi:10.1017/S0033291708003887

103. Ziauddeen H, Dibben C, Kipps C, Hodges JR, Mckenna PJ. Negative schizophrenic symptoms and the frontal lobe syndrome: one and the same? 
Eur Arch Psychiatry Clin Neurosci (2011) 261:59-67. doi:10.1007/s00406-0100133-y

104. Holthausen EAE, Wiersma D, Sitskoorn MM, Dingemans PM, Schene AH, Van Den Bosch RJ. Long-term memory deficits in schizophrenia: primary or secondary dysfunction? Neuropsychology (2003) 17:539-47. doi:10.1037/08944105.17.4.539

105. Raes F, Hermans D, Williams JM, Demyttenaere K, Sabbe B, Pieters G, et al. Is overgeneral autobiographical memory an isolated memory phenomenon in major depression? Memory (2006) 14:584-94. doi:10.1080/ 09658210600624614

106. Piolino P, Coste C, Martinelli P, Mace AL, Quinette P, Guillery-Girard B, et al. Reduced specificity of autobiographical memory and aging: do the executive and feature binding functions of working memory have a role? Neuropsychologia (2010) 48:429-40. doi:10.1016/j.neuropsychologia.2009.09.035

107. Ramponi C, Barnard PJ, Nimmo-Smith I. Recollection deficits in dysphoric mood: an effect of schematic models and executive mode? Memory (2004) 12:655-70. doi:10.1080/09658210344000189

108. Waters F, Maybery MT, Badcock JC, Michie PT. Context memory and binding in schizophrenia. Schizophr Res (2004) 68:119-25. doi:10.1016/S0920-9964(03) 00221-4

109. Danion JM, Rizzo L, Bruant A. Functional mechanisms underlying impaired recognition memory and conscious awareness in patients with schizophrenia. Arch Gen Psychiatry (1999) 56:639-44. doi:10.1001/archpsyc.56.7.639

110. Achim AM, Lepage M. Is associative recognition more impaired than item recognition memory in Schizophrenia? A meta-analysis. Brain Cogn (2003) 53:121-4. doi:10.1016/S0278-2626(03)00092-7

111. Yonelinas AP. The nature of recollection and familiarity: a review of 30 years of research. J Mem Lang (2002) 46:441-517. doi:10.1006/jmla.2002.2864

112. Eichenbaum H, Yonelinas AP, Ranganath C. The medial temporal lobe and recognition memory. Annu Rev Neurosci (2007) 30:123-52. doi:10.1146/ annurev.neuro.30.051606.094328

113. Heinrichs RW, Zakzanis KK. Neurocognitive deficit in schizophrenia: a quantitative review of the evidence. Neuropsychology (1998) 12:426-45. doi:10.1037/ 0894-4105.12.3.426

114. Toulopoulou T, Murray RM. Verbal memory deficit in patients with schizophrenia: an important future target for treatment. Expert Rev Neurother (2004) 4:43-52. doi:10.1586/14737175.4.1.43

115. Aleman A, Hijman R, De Haan EH, Kahn RS. Memory impairment in schizophrenia: a meta-analysis. Am J Psychiatry (1999) 156:1358-66.

116. Johnson-Selfridge M, Zalewski C. Moderator variables of executive functioning in schizophrenia: meta-analytic findings. Schizophr Bull (2001) 27:305-16. doi:10.1093/oxfordjournals.schbul.a006876

117. Reichenberg A, Harvey PD. Neuropsychological impairments in schizophrenia: integration of performance-based and brain imaging findings. Psychol Bull (2007) 133:833-58. doi:10.1037/0033-2909.133.5.833

118. Knowles EEM, David AS, Reichenberg A. Processing speed deficits in schizophrenia: reexamining the evidence. Am J Psychiatry (2010) 167:828-35. doi:10.1176/appi.ajp.2010.09070937

119. Laws KR, Mckenna PJ, Kondel TK. On the distinction between access and store disorders in schizophrenia: a question of deficit severity? Neuropsychologia (1998) 36:313-21. doi:10.1016/S0028-3932(97)00130-9

120. Pomarol-Clotet E, Hynes F, Ashwin C, Bullmore ET, Mckenna PJ, Laws KR. Facial emotion processing in schizophrenia: a non-specific neuropsychological deficit? Psychol Med (2010) 40:911-9. doi:10.1017/S0033291709991309

121. Markowitsch HJ, Welzer H. Das autobiographische Gedächtnis: Hirnorganische Grundlagen und biosoziale Entwicklung. Stuttgart: Klett-Cotta (2005).

122. Dos Santos V. MR-Morphometrische Veränderungen und ihre Assoziationen zur neuropsychologischen Testleistung bei Patienten mit einer Leichten kognitiven Beeinträchtigung und Alzheimer Demenz. Eine MRT-Studie mit optimierter voxelbasierter Morphometrie, Thesis. Heidelberg: University of Heidelberg (2009).

123. Sattler C. Kognitive Reserve im Alter - Wechselwirkungen neuropsychologischer, sozialer und neurobiologischer Faktoren im Vorfeld demenzieller Erkrankungen. Eine Analyse im Rahmen der Interdisziplinären Längsschnittstudie des Erwachsenenalters (ILSE), Thesis. Heidelberg: University of Heidelberg (2011).

124. Harrison PJ. The hippocampus in schizophrenia: a review of the neuropathological evidence and its pathophysiological implications. Psychopharmacology (Berl) (2004) 174:151-62. doi:10.1007/s00213-003-1761-y
125. Niizato K, Genda K, Nakamura R, Iritani S, Ikeda K. Cognitive decline in schizophrenics with Alzheimer's disease: a mini-review of neuropsychological and neuropathological studies. Prog Neuro Psychopharmacol Biol Psychiatr (2001) 25:1359-66. doi:10.1016/S0278-5846(01)00191-9

126. Mcbride T, Moberg PJ, Arnold SE, Mozley LH, Mahr RN, Gibney M, et al. Neuropsychological functioning in elderly patients with schizophrenia and Alzheimer's disease. Schizophr Res (2002) 55:217-27. doi:10.1016/S09209964(01)00232-8

127. Palmer BW, Bondi MW, Twamley EW, Thal L, Golshan S, Jeste DV. Are lateonset schizophrenia spectrum disorders neurodegenerative conditions? Annual rates of change on two dementia measures. J Neuropsychiatry Clin Neurosci (2003) 15:45-52. doi:10.1176/appi.neuropsych.15.1.45

128. Ting C, Rajji TK, Ismail Z, Tang-Wai DF, Apanasiewicz N, Miranda D, et al. Differentiating the cognitive profile of schizophrenia from that of Alzheimer disease and depression in late life. PLoS One (2010) 5:e10151. doi:10.1371/ journal.pone.0010151

129. Baldessarini RJ, Hegarty JD, Bird ED, Benes FM. Meta-analysis of postmortem studies of Alzheimer's disease-like neuropathology in schizophrenia. Am J Psychiatry (1997) 154:861-3.

130. Arnold SE, Trojanowski JQ, Gur RE, Blackwell P, Han L-Y, Choi C. Absence of neurodegeneration and neural injury in the cerebral cortex in a sample of elderly patients with schizophrenia. Arch Gen Psychiatry (1998) 55:225-32. doi:10.1001/archpsyc.55.3.225

131. Niizato K, Arai T, Kuroki N, Kase K, Iritani S, Ikeda K. Autopsy study of Alzheimer's disease brain pathology in schizophrenia. Schizophr Res (1998) 31:177-84. doi:10.1016/S0920-9964(98)00028-0

132. Powchik P, Davidson M, Haroutunian V, Gabriel SM, Purohit DP, Perl DP, et al. Postmortem studies in schizophrenia. Schizophr Bull (1998) 24:325-41. doi:10.1093/oxfordjournals.schbul.a033330

133. Purohit DP, Perl DP, Haroutunian V, Powchik P, Davidson M, Davis KL. Alzheimer disease and related neurodegenerative diseases in elderly patients with schizophrenia: a postmortem neuropathologic study of 100 cases. Arch Gen Psychiatry (1998) 55:205-11. doi:10.1001/archpsyc.55.3.205

134. Jellinger KA, Gabriel E. No increased incidence of Alzheimer's disease in elderly schizophrenics. Acta Neuropathol (1999) 97:165-9. doi:10.1007/ s004010050969

135. Religa D, Laudon H, Styczynska M, Winblad B, Naslund J, Haroutunian V. Amyloid beta pathology in Alzheimer's disease and schizophrenia. Am J Psychiatry (2003) 160:867-72. doi:10.1176/appi.ajp.160.5.867

136. Harvey PD, Reichenberg A, Bowie CR. Cognition and aging in psychopathology: focus on schizophrenia and depression. Ann Rev Clin Psych (2006) 2:389-409. doi:10.1146/annurev.clinpsy.2.022305.095206

137. Schröder J, Pantel J. Die leichte kognitive Beeinträchtigung: Klinik, Diagnostik, Therapie und Prävention im Vorfeld der Alzheimer-Demenz. Stuttgart: Schattauer (2011).

138. Sebastian C, Beer MD. Physical health problems in schizophrenia and other serious mental illnesses. J Psychiatr Intensive Care (2007) 3:101-11. doi:10. $1017 /$ s1742646407001148

139. Oud MJ, Meyboom-De Jong B. Somatic diseases in patients with schizophrenia in general practice: their prevalence and health care. BMC Fam Pract (2009) 10:32. doi:10.1186/1471-2296-10-32

140. Liu SK, Hiseh MH, Huang TJ, Liu CM, Liu CC, Hua MS, et al. Patterns and clinical correlates of neuropsychologic deficits in patients with schizophrenia. J Formos Med Assoc (2006) 105:978-91. doi:10.1016/S0929-6646(09) 60282-5

141. Irani F, Kalkstein S, Moberg EA, Moberg PJ. Neuropsychological performance in older patients with schizophrenia: a meta-analysis of cross-sectional and longitudinal studies. Schizophr Bull (2011) 37:1318-26. doi:10.1093/schbul/ sbq057

142. Woodward ND, Purdon SE, Meltzer HY, Zald DH. A meta-analysis of neuropsychological change to clozapine, olanzapine, quetiapine, and risperidone in schizophrenia. Int J Neuropsychopharmacol (2005) 8:457-72. doi:10.1017/ S146114570500516X

143. Thornton AE, Van Snellenberg JX, Sepehry AA, Honer W. The impact of atypical antipsychotic medications on long-term memory dysfunction in schizophrenia spectrum disorder: a quantitative review. J Psychopharmacol (2006) 20:335-46. doi:10.1177/0269881105057002 
144. Guilera G, Pino O, Gómez-Benito J, Rojo JE. Antipsychotic effects on cognition in schizophrenia: a meta-analysis of randomised controlled trials. Eur J Psychiatr (2009) 23:77-89. doi:10.4321/s0213-61632009000200002

145. Schröder J, Tittel A, Stockert A, Karr M. Memory deficits in subsyndromes of chronic schizophrenia. Schizophr Res (1996) 21:19-26. doi:10.1016/09209964(96)00027-8

146. Mishara AL, Goldberg TE. A meta-analysis and critical review of the effects of conventional neuroleptic treatment on cognition in schizophrenia: opening a closed book. Biol Psychiatry (2004) 55:1013-22. doi:10.1016/j.biopsych.2004. 01.027

147. Davidson M, Galderisi S, Weiser M, Werbeloff N, Fleischhacker WW, Keefe RS, et al. Cognitive effects of antipsychotic drugs in first-episode schizophrenia and schizophreniform disorder: a randomized, open-label clinical trial (eufest). Am J Psychiatry (2009) 166:675-82. doi:10.1176/appi.ajp.2008. 08060806

148. Henry JD, Crawford JR. A meta-analytic review of verbal fluency deficits in schizophrenia relative to other neurocognitive deficits. Cogn Neuropsychiatry (2005) 10:1-33. doi:10.1080/13546800344000309

149. Alvarez P, Squire LR. Memory consolidation and the medial temporal lobe: a simple network model. Proc Nat Acad Sci U S A (1994) 91:7041-5. doi:10.1073/pnas.91.15.7041

150. Maguire EA, Nannery R, Spiers HJ. Navigation around London by a taxi driver with bilateral hippocampal lesions. Brain (2006) 129:2894-907. doi:10.1093/ brain/awl286

151. Leyhe T, Müller S, Eschweiler GW, Saur R. Deterioration of the memory for historic events in patients with mild cognitive impairment and early Alzheimer's disease. Neuropsychologia (2010) 48:4093-101. doi:10.1016/ j.neuropsychologia.2010.10.011

152. Meeter M, Murre JMJ. Consolidation of long-term memory: evidence and alternatives. Psychol Bull (2004) 130:843-57. doi:10.1037/0033-2909.130. 6.843

153. Gorno-Tempini ML, Price CJ. Identification of famous faces and buildings: a functional neuroimaging study of semantically unique items. Brain (2001) 124:2087-97. doi:10.1093/brain/124.10.2087

154. Gobbini MI, Leibenluft E, Santiago N, Haxby JV. Social and emotional attachment in the neural representation of faces. Neuroimage (2004) 22:1628-35. doi:10.1016/j.neuroimage.2004.03.049

155. Rosenbaum RS, Gao F, Richards B, Black SE, Moscovitch M. "Where to?" Remote memory for spatial relations and landmark identity in former taxi drivers with Alzheimer's disease and encephalitis. J Cogn Neurosci (2005) 17:446-62. doi:10.1162/0898929053279496

156. Westmacott R, Black SE, Freedman M, Moscovitch M. The contribution of autobiographical significance to semantic memory: evidence from Alzheimer's disease, semantic dementia, and amnesia. Neuropsychologia (2003) 42:25-48. doi:10.1016/S0028-3932(03)00147-7

157. Westmacott R, Moscovitch M. The contribution of autobiographical significance to semantic memory. Mem Cognit (2003) 31:761-74. doi:10.3758/ BF03196114

158. Gilboa A, Winocur G, Grady CL, Hevenor SJ, Moscovitch M. Remembering our past: functional neuroanatomy of recollection of recent and very remote personal events. Cereb Cortex (2004) 14:1214-25. doi:10.1093/cercor/ bhh082

159. Piolino P, Giffard-Quillon G, Desgranges B, Chetelat G, Baron JC, Eustache F. Re-experiencing old memories via hippocampus: a PET study of autobiographical memory. Neuroimage (2004) 22:1371-83. doi:10.1016/j.neuroimage. 2004.02 .025

160. Rekkas PV, Constable RT. Evidence that autobiographic memory retrieval does not become independent of the hippocampus: an fMRI study contrasting very recent with remote events. J Cogn Neurosci (2005) 17:1950-61. doi:10.1162/089892905775008652

161. Maguire EA. Neuroimaging studies of autobiographical event memory. Philos Trans R Soc Lond, Ser B: Biol Sci (2001) 356:1441-51. doi:10.1098/rstb. 2001.0944

162. Svoboda E, Mckinnon MC, Levine B. The functional neuroanatomy of autobiographical memory: a meta-analysis. Neuropsychologia (2006) 44:2189-208. doi:10.1016/j.neuropsychologia.2006.05.023

163. Grön G, Wunderlich AP, Spitzer M, Tomczak R, Riepe MW. Brain activation during human navigation: gender-different neural networks as substrate of performance. Nat Neurosci (2000) 3:404-8. doi:10.1038/73980
164. Burgess N, Maguire EA, Spiers HJ, O’keefe J. A temporoparietal and prefrontal network for retrieving the spatial context of lifelike events. Neuroimage (2001) 14:439-53. doi:10.1006/nimg.2001.0806

165. Maguire EA. Neuroimaging, memory and the human hippocampus. Rev Neurol (Paris) (2001) 157:791-4.

166. Burgess N, Maguire EA, O'keefe J. The human hippocampus and spatial and episodic memory. Neuron (2002) 35:625-41. doi:10.1016/S0896-6273(02) 00830-9

167. Henson R. A mini-review of $\mathrm{fMRI}$ studies of human medial temporal lobe activity associated with recognition memory. Q J Exp Psychol B (2005) 58:340-60. doi:10.1080/02724990444000113

168. Chen KH, Chuah LY, Sim SK, Chee MW. Hippocampal region-specific contributions to memory performance in normal elderly. Brain Cogn (2010) 72:400-7. doi:10.1016/j.bandc.2009.11.007

169. Spiers HJ, Maguire EA, Burgess N. Hippocampal amnesia. Neurocase (2001) 7:357-82. doi:10.1076/neur.7.5.357.16245

170. Gabrieli JD, Brewer JB, Desmond JE, Glover GH. Separate neural bases of two fundamental memory processes in the human medial temporal lobe. Science (1997) 276:264-6. doi:10.1126/science.276.5310.264

171. Zeineh MM, Engel SA, Thompson PM, Bookheimer SY. Dynamics of the hippocampus during encoding and retrieval of face-name pairs. Science (2003) 299:577-80. doi:10.1126/science. 1077775

172. Schacter DL, Wagner AD. Medial temporal lobe activations in fMRI and PET studies of episodic encoding and retrieval. Hippocampus (1999) 9:7-24. doi:10.1002/(SICI) 1098-1063(1999)9:5<575::AID-HIPO11>3.0.CO;2-K

173. Greicius MD, Krasnow B, Boyett-Anderson JM, Eliez S, Schatzberg AF, Reiss $\mathrm{AL}$, et al. Regional analysis of hippocampal activation during memory encoding and retrieval: fMRI study. Hippocampus (2003) 13:164-74. doi:10.1002/ hipo. 10064

174. Ludowig E, Trautner P, Kurthen M, Schaller C, Bien CG, Elger CE, et al. Intracranially recorded memory-related potentials reveal higher posterior than anterior hippocampal involvement in verbal encoding and retrieval. $J \operatorname{Cog} n$ Neurosci (2008) 20:841-51. doi:10.1162/jocn.2008.20507

175. Tsukiura T, Fujii T, Okuda J, Ohtake H, Kawashima R, Itoh M, et al. Timedependent contribution of the hippocampal complex when remembering the past: a PET study. Neuroreport (2002) 13:2319-23. doi:10.1097/01.wnr. 0000044989.13025 .79

176. Maguire EA, Frith CD. Aging affects the engagement of the hippocampus during autobiographical memory retrieval. Brain (2003) 126:1511-23. doi:10.1093/brain/awg157

177. Maguire EA, Frith CD. Lateral asymmetry in the hippocampal response to the remoteness of autobiographical memories. J Neurosci (2003) 23: 5302-7.

178. Piefke M, Weiss PH, Zilles K, Markowitsch HJ, Fink GR. Differential remoteness and emotional tone modulate the neural correlates of autobiographical memory. Brain (2003) 126:650-68. doi:10.1093/brain/awg064

179. Daselaar SM, Fleck MS, Dobbins IG, Madden DJ, Cabeza R. Effects of healthy aging on hippocampal and rhinal memory functions: an event-related fMRI study. Cereb Cortex (2006) 16:1771-82. doi:10.1093/cercor/bhj112

180. Sanfilipo M, Lafargue T, Rusinek H, Arena L, Loneragan C, Lautin A, et al. Cognitive performance in schizophrenia: relationship to regional brain volumes and psychiatric symptoms. Psychiatry Res (2002) 116:1-23. doi:10.1016/ S0925-4927(02)00046-X

181. Nestor PG, Kubicki M, Kuroki N, Gurrera RJ, Niznikiewicz M, Shenton $\mathrm{ME}$, et al. Episodic memory and neuroimaging of hippocampus and fornix in chronic schizophrenia. Psychiatry Res (2007) 155:21-8. doi:10.1016/j. pscychresns.2006.12.020

182. Szeszko PR, Strous RD, Goldman RS, Ashtari M, Knuth KH, Lieberman JA, et al. Neuropsychological correlates of hippocampal volumes in patients experiencing a first episode of schizophrenia. Am J Psychiatry (2002) 159:217-26. doi:10.1176/appi.ajp.159.2.217

183. Ellison-Wright I, Glahn DC, Laird AR, Thelen SM, Bullmore E. The anatomy of first-episode and chronic schizophrenia: an anatomical likelihood estimation meta-analysis. Am J Psychiatry (2008) 165:1015-23. doi:10.1176/appi.ajp. 2008.07101562

184. Glahn DC, Laird AR, Ellison-Wright I, Thelen SM, Robinson JL, Lancaster JL, et al. Meta-analysis of gray matter anomalies in schizophrenia: application of anatomic likelihood estimation and network analysis. Biol Psychiatry (2008) 64:774-81. doi:10.1016/j.biopsych.2008.03.031 
185. Ellison-Wright I, Bullmore E. Meta-analysis of diffusion tensor imaging studies in schizophrenia. Schizophr Res (2009) 108:3-10. doi:10.1016/j.schres.2008. 11.021

186. Lipska BK, Weinberger DR. A neurodevelopmental model of schizophrenia: neonatal disconnection of the hippocampus. Neurotox Res (2002) 4:469-75. doi:10.1080/1029842021000022089

187. Wolf RC, Höse A, Frasch K, Walter H, Vasic N. Volumetric abnormalities associated with cognitive deficits in patients with schizophrenia. Eur Psychiatr (2008) 23:541-8. doi:10.1016/j.eurpsy.2008.02.002

188. Harms MP, Wang L, Csernansky JG, Barch DM. Structure-function relationship of working memory activity with hippocampal and prefrontal cortex volumes. Brain Struct Funct (2013) 218:173-86. doi:10.1007/s00429-0120391-8

189. Di X, Chan RCK, Gong Q-Y. White matter reduction in patients with schizophrenia as revealed by voxel-based morphometry: an activation likelihood estimation meta-analysis. Progr Neuro Psychopharmacol Biol Psychiatr (2009) 33:1390-4. doi:10.1016/j.pnpbp.2009.08.020

190. Schlösser, RGM, Nenadic I, Wagner G, Güllmar D, Von Consbruch K, Köhler S, Schultz CC, et al. White matter abnormalities and brain activation in schizophrenia: a combined DTI and fMRI study. Schizophr Res (2007) 89:1-11. doi:10.1016/j.schres.2006.09.007

191. Kubicki M. Neurocognition and white matter imaging: can the relationship be reliably quantified? Am J Psychiatry (2010) 167:373-5. doi:10.1176/appi.ajp. 2010.10010139
192. Liu X, Lai Y, Wang X, Hao C, Chen L, Zhou Z, et al. Reduced white matter integrity and cognitive deficit in never-medicated chronic schizophrenia: a diffusion tensor study using TBSS. Behav Brain Res (2013) 252:157-63. doi:10.1016/j.bbr.2013.05.061

Conflict of Interest Statement: The authors declare that the research was conducted in the absence of any commercial or financial relationships that could be construed as a potential conflict of interest.

Received: 12 January 2015; accepted: 28 March 2015; published online: 21 April 2015. Citation: Herold CJ, Lässer MM, Schmid LA, Seidl U, Kong L, Fellhauer I, Thomann PA, Essig M and Schröder J (2015) Neuropsychology, autobiographical memory, and hippocampal volume in "younger" and "older" patients with chronic schizophrenia. Front. Psychiatry 6:53. doi: 10.3389/fpsyt.2015.00053

This article was submitted to Schizophrenia, a section of the journal Frontiers in Psychiatry.

Copyright (C) 2015 Herold, Lässer, Schmid, Seidl, Kong, Fellhauer, Thomann, Essig and Schröder. This is an open-access article distributed under the terms of the Creative Commons Attribution License (CC BY). The use, distribution or reproduction in other forums is permitted, provided the original author(s) or licensor are credited and that the original publication in this journal is cited, in accordance with accepted academic practice. No use, distribution or reproduction is permitted which does not comply with these terms. 